IZA DP No. 7932

Ambiguity on Audits and Cooperation in a Public Goods Game

Zhixin Dai

Robin M. Hogarth

Marie Claire Villeval

January 2014 


\title{
Ambiguity on Audits and Cooperation in a Public Goods Game
}

\author{
Zhixin Dai \\ Université de Lyon, CNRS, GATE \\ Robin M. Hogarth \\ Universitat Pompeu Fabra \\ and Barcelona GSE \\ Marie Claire Villeval \\ Université de Lyon, CNRS, GATE \\ and IZA \\ Discussion Paper No. 7932
January 2014 \\ IZA \\ P.O. Box 7240 \\ 53072 Bonn \\ Germany \\ Phone: +49-228-3894-0 \\ Fax: +49-228-3894-180 \\ E-mail: iza@iza.org
}

Any opinions expressed here are those of the author(s) and not those of IZA. Research published in this series may include views on policy, but the institute itself takes no institutional policy positions. The IZA research network is committed to the IZA Guiding Principles of Research Integrity.

The Institute for the Study of Labor (IZA) in Bonn is a local and virtual international research center and a place of communication between science, politics and business. IZA is an independent nonprofit organization supported by Deutsche Post Foundation. The center is associated with the University of Bonn and offers a stimulating research environment through its international network, workshops and conferences, data service, project support, research visits and doctoral program. IZA engages in (i) original and internationally competitive research in all fields of labor economics, (ii) development of policy concepts, and (iii) dissemination of research results and concepts to the interested public.

IZA Discussion Papers often represent preliminary work and are circulated to encourage discussion. Citation of such a paper should account for its provisional character. A revised version may be available directly from the author. 


\section{ABSTRACT \\ Ambiguity on Audits and Cooperation in a Public Goods Game $^{\star}$}

We investigate the impact of various audit schemes on the future provision of public goods, when contributing less than the average of the group is sanctioned exogenously and the probability of an audit is unknown. We study how individuals update their beliefs about the probability of being audited, both before and after audits are definitely withdrawn. We find that when individuals have initially experienced systematic audits, they decrease both their beliefs and their contributions almost immediately after audits are withdrawn. In contrast, when audits were initially less frequent and more irregular, they maintain high beliefs about the probability of being audited and continue cooperating long after audits have been withdrawn. Inconsistency in experiencing audits across time clearly increases the difficulty of learning the true audit probabilities. Thus, conducting less frequent and irregular audits with higher fines can increase efficiency dramatically.

JEL Classification: C92, H41, D83

Keywords: ambiguity, audits, sanctions, beliefs, cooperation, public goods, experiment

Corresponding author:

Marie Claire Villeval

GATE

CNRS - University of Lyon

93 Chemin des Mouilles

69130 Ecully

France

E-mail: villeval@gate.cnrs.fr

\footnotetext{
${ }^{*}$ We are grateful to O. Armantier, N. Houy, K. Konrad, L. S. Robin, J.R. Tyran, L. Vesterlund, and participants to the workshop on taxation and redistribution at the Max Planck Institute for Tax Law and Public Finance in Munich, to the ESA meeting in New-York, the AFSEE meeting in Montpellier, the BEE workshop in Toulouse, and the $11^{\text {th }}$ Journees Louis-Andre Gérard-Varet in Marseille for useful comments. This research has been supported by a grant from the French National Research Agency (ANR, EMCO program, HEIDI grant, ANR-11-EMCO-011-01) and was performed within the framework of the LABEX CORTEX (ANR-11-LABX-0042) of Universite de Lyon, within the program Investissements d'Avenir (ANR-11-IDEX-007) operated by the French National Research Agency (ANR). Hogarth gratefully recognizes the financial support of the Spanish Ministerio de Economía y Competitividad (Grant ECO2012-35545).
} 


\section{INTRODUCTION}

It is well known that the provision of public goods suffers from free-riding (Samuelson, 1954; Marwell and Ames, 1981; Isaac et al., 1986; Andreoni, 1988; Ledyard, 1995). Peer punishment is able to increase cooperation (Fehr and Gächter, 2000; Masclet et al., 2003; Bochet et al., 2006; Carpenter, 2007; Egas and Riedl, 2008), but it has detrimental effects such as efficiency losses in the short run (Fehr and Gächter, 2000; Houser et al., 2008). It may alter altruistic cooperation (Fehr and Rockenbach, 2003), especially if reprisals are possible (Nikiforakis, 2008; Denant-Boémont et al., 2007). Replacing peer punishment with legal sanctions (Polinsky and Shavell, 2000), whether deterrent or not (Tyran and Feld, 2006), or subsidies and taxes (Andreoni and Bergstrom, 1995; Falkinger, 1996) may solve some of these problems. In particular, sanctioning negative deviations and rewarding positive deviations from the mean contribution of group members can be self-financing for the same income class and increase efficiency (Falkinger et al., 2000). The mechanism assumes that deviations are measured continuously. This may entail, however, excessively high auditing costs and individuals may reject a society that monitors their actions continuously.

In this paper we study how to improve the efficiency of an exogenous sanction mechanism in a public goods game by exploring the impact of ambiguity about the occurrence of audits and manipulating their probability and regularity in a dynamic setting. By ambiguity we mean that individuals are not provided with information about the probabilities of audits but can only infer 
these from experience (Ellsberg, 1961). By varying the pattern of audit sequences, we analyze

how individuals adjust their contributions after experiencing a sequence of continuous audits $v s$. a sequence of less frequent and irregular audits with higher sanctions. We hypothesize that cooperation can be sustained longer after experiencing irregular audit sequences than continuous audits. If people do not know the probability of an audit, (ir)regularity might condition the capacity to learn the true audit probability and thus, impact the evaluation of costs and benefits of contributing. Indeed, in a different framework it has been shown that, under ambiguity, intermittent reinforcers have greater effects on individual behavior than continuous reinforcers even after a regime shift. ${ }^{1}$ Similarly, Bereby-Meyer and Roth (2006) have shown that learning in repeated games is much slower when incentives involve probabilistic rather than continuous reinforcement. This could explain that in real settings like speed regulation, public transportation or tax policy, audit frequencies are often both ambiguous and dynamic. ${ }^{2}$

However, if previous studies have found a positive effect of uncertainty on compliance (Friedland, 1982; de Angelo and Charness, 2012; Tan and Yim, 2013), others have shown that

\footnotetext{
${ }^{1}$ Psychologists have shown that if organisms are continuously reinforced for specific acts during a training phase, then those acts will cease in an extinction phase when the reinforcement is eliminated. However, if reinforcement is irregular during training, the behavior will persist for some time in the extinction phase, that is, after the reinforcement has been eliminated (Ferster and Skinner, 1957; Hilgard and Bower, 1975). Hogarth and Villeval (2014) provide an economic analysis of this phenomenon applied to incentives and rewards.

${ }^{2}$ Speed radars are not always located at the same place, meaning that audits are sometimes systematic and sometimes inexistent. Similarly, audits in public transportation are concentrated on certain lines during a while and then move to other lines. Tax authorities deliberately maintain uncertainty in their audit selection process in order to increase compliance. The variations in audit frequency and regularity may also result from a non-deliberate policy. For example, in times of budget restrictions the frequency of tax audits may be reduced. Thus, the impact on compliance may differ according to whether audits were previously regular or not.
} 
less uncertainty may lead to better outcomes. In particular, Alm et al. (1992) found that a stronger link between the tax payment and the receipt of public goods leads to a negative effect of uncertainty on compliance. This could explain that we also observe in real settings examples of continuous audits to ensure higher deterrence (e.g., video cameras at traffic lights, screening of passengers at airports, fixed radars). Thus, it is unclear a priori whether ambiguity and higher irregularity of audits improve or not norm adherence in contributions to public goods.

To address this question, we have designed a three-player linear public goods game in which negative deviations from the mean contribution of the other group members trigger a sanction in case of an audit. Different from Falkinger (1996), positive deviations are not rewarded for the sake of simplification. Also, in sharp contrast with previous literature (notably, Alm et al., 1992; Mittone, 2006; Kastlunger et al., 2009; de Angelo and Charness, 2012), players are not informed about the audit probability; instead, they must infer this from experience, i.e., by participating in the game. Moreover, while the game lasts 50 periods, a regime shift is introduced by eliminating audits after period 22 .

Before the regime shift, the frequency of audits and the severity of sanctions vary across treatments. In the Continuous treatment, each of the first 22 periods is audited. In the Intermittent 7 treatment, only seven audits are randomly assigned across periods but the severity of sanctions is tripled (to maintain approximately the same expected cost of sanction for a risk-neutral subject). These two main treatments allow us to measure how the irregularity and the frequency of audits 
affect beliefs and contribution behavior after audits are withdrawn definitively. In variants, we reduce further the number of audits (Intermittent 5 and 3) or we apply the same sanction severity as in the Continuous treatment (Intermittent 7 Low Fine), to test both the sensitivity of behavior to the number of audits and to isolate the effect of audit irregularity from the effect of the level of fines.

Our results show that when there is ambiguity about the probability of audits, efficiency throughout the 50 periods of the game is improved by the use of an intermittent audit scheme, provided frequency of audits and sanctions before the regime shift are sufficiently high. Indeed, in the Continuous treatment players learn to coordinate on a high contribution level before the regime shift but then free ride almost immediately after audits are withdrawn. In contrast, although individuals in the Intermittent 7 treatment contribute as much as those in the Continuous treatment before the regime shift, the decay of cooperation occurs long after the regime shift and is much smoother than in the Continuous treatment. This is mainly due to a stronger anchoring of beliefs about the audit probability based on past experience, and consequently a lower reaction to prediction errors. On the other hand, in the Continuous treatment players can update beliefs based on the prediction error from the previous period because there is much less variability in the occurrence of audits. Thus, in this treatment beliefs drop sharply immediately after the regime shift and drive contributions downward whereas in the Intermittent 7 treatment beliefs decrease slowly and smoothly after the regime shift and they remain higher than in the Continuous 
treatment through the end. The policy implications are important, especially if one considers the cost of audits in real settings. We derive recommendations about the alternation of sequences with and without audits and the randomization of audits across time when audits are ambiguous. The remainder of our paper is organized as follows. Section 2 surveys briefly the related literature. Section 3 describes the experimental design and procedures and states our predictions. Section 4 reports the experimental results while Section 5 discusses these results and concludes.

\section{RELATED LITERATURE}

Several theories have explored the role of uncertainty on compliance with norms. For example, Lazear (2006) shows theoretically that to maximize the efficiency of learning, it is better to inform individuals that they will be tested when learning and monitoring are costly, but not when they are easy. Eeckhout et al. (2010) propose an incentive-based theory to examine whether random crackdowns, i.e. intermittent periods of high intensity policing, can be an optimal deterrence policy. A difference with our approach is that crackdowns are publicized, so that people are informed in advance about this high intensity period of monitoring. On the contrary, we focus here on learning in an ambiguous environment. In law and economics, some theories argue that maximizing uncertainty helps deter crime, as individuals cannot assess precisely the true risk of engaging in such actions (Ross, 1984; Harel and Segal, 1999; Bebchuk and Kaplow, 1992). In the domain of taxes, Snow and Warren (2005a) show theoretically that greater uncertainty about audit probability only encourages compliance by ambiguity averse taxpayers 
and Snow and Warren (2005b) find that increased uncertainty about the evaded amount detected by an audit can only increase compliance if prudent individuals believe that a substantial fraction will be detected. Snow and Warren (2007) show that Bayesian updating of subjective beliefs about the probability of an audit can result in more tax evasion than would occur in the absence of such updating, which suggests that creating uncertainty could be counterproductive. These studies, however, do not consider regime shifts between different patterns of audits.

Using laboratory experiments on tax compliance, Friedland (1982) has shown that imprecise information on audits increases compliance. Comparing the effects of increasing uncertainty between taxation and public goods situations, Alm et al. (1992) found that uncertainty increases compliance for the former, but not for the latter. Tan and Yim (2013) compare a tax regime with a maximum number of audits and strategic uncertainty to a standard flat-rate rule; they find that high strategic uncertainty increases compliance. In a roadway speeding framing, de Angelo and Charness (2012) implement uncertainty over a deterrence regime by means of compound lotteries and show that increased uncertainty lowers the violation rate (see also Backer et al., 2003). On the other hand, Spicer and Thomas (1982) did not find a positive effect of uncertainty on tax compliance. Our work differs from those above in that our aim is not to explore the impact of ambiguity per se. Instead, we maintain ambiguity about audits but manipulate their sequence and vary their probability to investigate how compliance is affected by experiencing regular $v s$. 
irregular audits before audits are withdrawn. ${ }^{3}$

Our approach is close to that of Kastlunger et al. (2009). They compare compliance in a tax game when the audit pattern is continuous at the beginning of the game and intermittent afterwards, and when the audit pattern occurs every second round. Subjects know the mean audit probability (15\%) but not its distribution over the life span. Compliance over the life span is higher when audits are concentrated in early as opposed to later periods; and compliance decreases when subjects are not audited over a long period of time. Similarly, we manipulate the patterns of audit sequences and we study how past experience induces a learning process. Major differences are that we consider a public goods game instead of a tax game and subjects are not informed about the overall probability of audits. ${ }^{4}$ Moreover in our game, the same subjects do not experience the continuous and the intermittent audit patterns.

\section{EXPERIMENTAL DESIGN AND PREDICTIONS}

\subsection{Treatments}

The experiment consists of two main treatments: the Continuous treatment and the Intermittent 7 treatment. In three additional treatments, we manipulate the frequency of audits (Intermittent 5 and Intermittent 3 treatments) or the severity of sanctions (Intermittent 7 low fine treatment).

Continuous treatment. The Continuous treatment consists of a linear public goods game

3 We also differ from Muehlbacher et al. (2012) who show that taxpayers comply more when they have to wait longer before knowing the outcome of an audit. In our paper, ambiguity relates to the probability of an audit, not to the realization of the audit.

${ }^{4}$ Maciejovsky et al. (2007) also study the effect of various time lags between audits but without ambiguity. 
played over 50 periods. We form groups of three members that remain fixed throughout the session. At the beginning of each period, each group member is endowed with 20 ECU (Experimental Currency Units) and has to decide how many ECU to contribute to a public account. Each period consists of three stages (belief elicitation, contribution, punishment).

In the contribution stage, group members have to choose how many ECU of their endowment (between 0 and 20) to contribute to a group account, with the remainder being kept in their private account. The total amount contributed to the public account by the three group members is shared equally among them and the marginal per capita return of the public account is 0.5 . The payoff function for each group member in the contribution stage can be written:

$$
\pi_{i}^{1}=\left(20-c_{i}+0.5 * \sum_{k=1}^{3} c_{k}\right)
$$

where $c_{i}$ is the individual's contribution, and $c_{k}$ that of each group member, $k=1,2,3$.

The next stage involves the punishment. In some periods, the three group members' contributions are audited exogenously. If the audit reveals that one or two group members have contributed less than the average of the two other group members, a fine reduces their first-stage payoff. The fine is 1.25 times the difference between the mean contribution of the two other group members and the individual's contribution. If there is no audit in the period or if the audit reveals that the individual did not contribute less than the average of the two other group members, the payoff from the contribution stage is not modified. This mechanism differs from that proposed by Falkinger (1996) in that we do not reward positive deviations from the mean 
contribution. ${ }^{5}$ At the end of the punishment stage, the payoff function becomes:

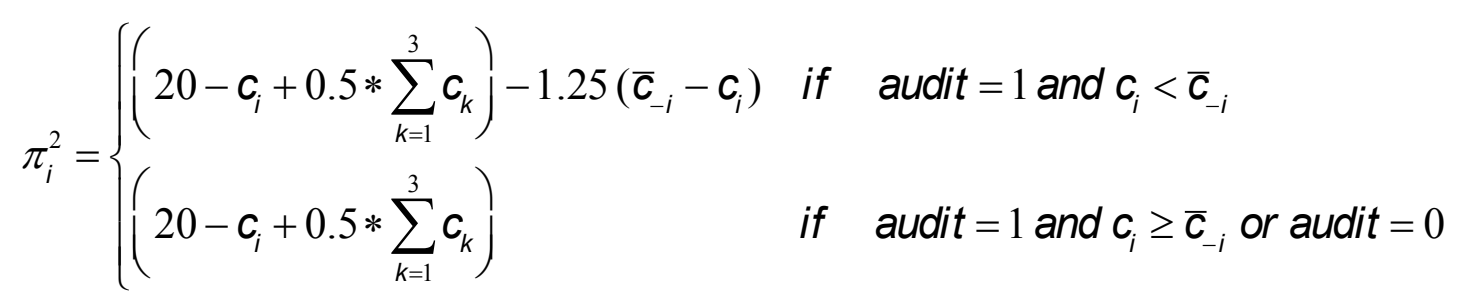

where $\bar{c}_{-i}$ is the average contribution of the two other group members.

In addition to strategic uncertainty about others' contributions, the environment is ambiguous. Individuals are not informed about the probability that contributions will be audited in a specific period. Nor do they know ex ante the total number of audits in a session. They are only informed at the beginning of the session that the group may be audited in some periods. At the end of each period, the participants receive feedback on the total group contribution, the audit realization, and the amount of their own payoff net of the fine, if any. Thus, they have to learn the audit probability from the past sequence of experienced audits. In fact, contributions are audited in each of the first 22 periods. Then, from periods 23 through 50, we remove audits definitively. No participant is informed about this. The objective of the regime shift is to measure the number of periods participants take to realize that there are no more audits.

At the beginning of each period, we elicit the subjects' subjective belief about the occurrence of an audit. Before choosing their contribution, they have to report an integer between 0 and 100

\footnotetext{
5 It should be noted that in the public goods games where sanctions are decided by group members, it is usually observed that group members sanction the individual deviations from the average contribution of others (Fehr and Gächter, 2000; Masclet et al., 2003). The average contribution is usually considered as the norm of the group.
} 
to indicate their belief about the number of chances out of 100 that an audit will occur in the current period. ${ }^{6}$ Belief elicitation is incentivized (Gächter and Renner, 2010; Wang, 2011) according to the quadratic scoring rule as in Nyarko and Schotter (2002). Specifically, participants receive 2 Euros minus a number that varies negatively with the accuracy of their predictions. The penalty is twice the squared deviation between the report and the true outcome. Suppose the reported number is $\delta$, then the payoff from the prediction is given by:

$$
\pi^{P}=\left\{\begin{array}{l}
2-2 *\left(1-\frac{\partial}{100}\right)^{2} \text { if } \text { audit }=1 \\
2-2 *\left(\frac{\partial}{100}\right)^{2} \text { if } \text { audit }=0
\end{array}\right.
$$

Deterministic forecasts of 0 and 100 can lead to the worst and best possible payoffs of $€ 0$ and $€ 2$. Participants were informed that the best strategy to maximize payoffs is to state their true belief about the number of chances that an audit will occur.

Participants are paid the sum of the payoffs for each of the 50 periods of the game plus the payoff from the prediction made in one of the 50 periods, randomly drawn at the end of the session. We only pay for one prediction to limit the risk of hedging (see Blanco et al., 2010).

Intermittent 7 treatment. This treatment introduces two changes compared with the Continuous treatment. The first is that audits occur intermittently before the regime shift. On average, there is an audit every three periods and we impose that seven periods are audited in

\footnotetext{
${ }^{6}$ Eliciting beliefs about the probability of being audited instead of simply asking whether subjects believe that this period will be audited or not causes less identification problems (see Manski, 2004). However, with quadratic scoring rules, risk aversion increases the likelihood that subjects report a probability of 0.5 .
} 
each group in the first 22 periods. This includes an audit in period 22 such that the last audited period is the same across treatments. The other audits are independently and randomly distributed in the groups. As in the Continuous treatment, no more audits are implemented after period 22, and the number, frequency and distribution of audits are not made common knowledge. The second change is that the fine parameter is three times higher than in the Continuous treatment (3.75 instead of 1.25). We compensate the lower probability of an audit with a higher sanction, so that the expected cost of a sanction is similar across treatments for a risk-neutral individual. The payoff function is:

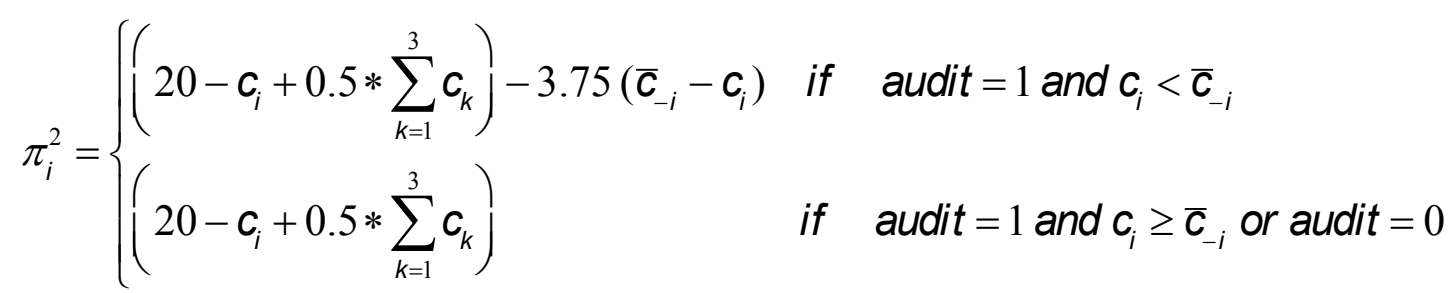

The strategic uncertainty is the same as in the Continuous treatment. So if we observe behavioral differences between this treatment and the previous one, they should be attributed to the individuals' reactions to the intermittence of audits.

Additional treatments. To study the sensitivity of contributions to levels of intermittence, we designed two additional treatments in which the number of audits is decreased. The Intermittent 5 and Intermittent 3 treatments are similar to the Intermittent 7 treatment, except that only five and three audits, respectively, occur in the first 22 periods instead of seven. As before this is not made common knowledge. In order to isolate the effect of the intermittence of audits on decisions, we also designed a variant of the Intermittent 7 treatment in which the severity of sanctions is the 
same as in the Continuous treatment. In this Intermittent 7 Low Fine treatment, the sanction parameter is 1.25 while it is 3.75 in the Intermittent 7 treatment.

Elicitation of attitudes towards, risk, ambiguity and losses. Before reading the instructions of the game, we elicited participants' attitudes toward risk and uncertainty by asking them to price both a clear bet and a vague bet following a procedure similar to that of Fox and Tversky (1995). ${ }^{7,8}$ Only one of the two sets of decisions was randomly drawn for payment at the end of the session. Then, loss aversion in risky choice tasks was elicited using the same procedure as in Gächter et al. (2010). ${ }^{9}$ These decisions are made at the beginning of the session but their outcomes are determined only after the public goods game has been completed (thus avoiding income effects).

7 Subjects make a first set of 20 decisions between accepting a certain payoff and drawing a ball in an urn that contains 5 blue balls and 5 yellow balls (a risky lottery). The amount of the certain payoff increases from 0.25 eurocents to $€ 5$. One yellow ball drawn from the run pays $€ 5$, a blue ball pays nothing. Then, subjects have to make a second set of 20 similar decisions except that the proportions of yellow and blue balls in the urn are now unknown (an ambiguous lottery). At the end of the session, the program randomly determines which urn is used for payment. For this urn it randomly draws a number between 1 and 20 to determine which of the 20 decisions matters for determining the participant's earnings. If the participant has chosen the certain amount, this amount is added to his other earnings. If he has instead chosen to draw a ball, the program draws a ball from the selected urn. If a yellow ball is drawn, it pays $€ 5$. In both sets of decisions, a risk neutral participant should choose to draw a ball from the urn until the certain payoff is equal to at least $€ 2.5$. In the first set of decisions, a risk averse (seeking) subject should switch to the certain payoff for lower (higher) certain amounts. An ambiguity averse (seeking) subject should switch for lower (higher) certain amounts in the second set of decisions than in the first one.

${ }^{8}$ We acknowledge that it could have been more relevant to elicit attitudes towards ambiguity in the domain of losses instead of in the domain of gains. However, our procedure allowed us to use the same lotteries to elicit the attitudes towards risk and ambiguity. This kept the procedure simple.

${ }^{9}$ Each participant makes six successive decisions between participating or not in a lottery. In the lottery choices the winner's prize is fixed at $€ 6$ whereas the loser's prize increases incrementally from - $€ 2$ in the first lottery choice to - $€ 7$ in the sixth lottery choice. Refusing to participate in a lottery guarantees the individual that he will earn nothing and lose nothing. Loss neutrality supports the decision to play the first five lotteries since their expected payoff is positive or null. Loss aversion can lead the participant to reject other lotteries. 


\subsection{Predictions}

Let us first assume that players are able to anticipate whether an audit occurs or not. In the case of no audit, free-riding is a dominant strategy since the marginal per capital return from the group account is smaller than that from the private account. In case of an audit, it is trivial to show that each possible level of contribution is a Nash equilibrium, as there is no sanction if all contribute the same. Indeed, sanctions are credible because they are exogenously imposed. Full contribution is a payoff dominant Nash equilibrium. Let us now assume that individuals have the same prior beliefs about the probability of being audited and they are risk neutral. In the Continuous treatment (and in the Intermittent 7 Low Fine), they should contribute 20 if they believe that the probability of being audited is greater than $40 \%$, and 0 otherwise. In the intermittent $7 / 5 / 3$ treatments, they should contribute 20 if they believe that the probability of being audited is greater than $13 \%$, and 0 otherwise (see Appendix A for the proof).

Participants have to infer the actual probability of an audit from their past experience. The investigation of how beliefs are updated is crucial to predict behavior. We assume that at the beginning of each period, participants update their belief based on their past experience of audits up to that point. We further assume that they are boundedly rational in that they update their belief not according to Bayes' rule ${ }^{10}$ but to a less cognitively demanding Bayesian-like process (see Hogarth and Einhorn, 1992, and Hogarth and Villeval, 2014). We assume a simple

10 Gilboa et al. (2008) argue that the Bayesian model is too restrictive in that beliefs are seldom specific enough to define a unique probability distribution and too general in that it offers no insight into how prior beliefs are formed. 
anchoring-and-adjustment process whereby judgment is anchored on the previous assessment and updated by the experience of the latest period. This is expressed as follows:

$$
S_{k}=S_{k-1}+w_{k}\left[s\left(x_{k}\right)-S_{k-1}\right]
$$

where $S_{k}$ is the belief that the next period will be audited after experiencing $k$ periods with $0 \leq S_{k}$ $\leq 1 ; S_{k-1}$ is the belief that the previous period would be audited; $s\left(x_{k}\right)$ indicates whether the $k^{\text {th }}$ period was audited (with $s\left(x_{k}\right)=1$ ) or not (with $s\left(x_{k}\right)=0$ ); and $w_{k}$ is an adjustment parameter that determines how the latest evidence modifies the previous assessment. ${ }^{11}$ It is assumed proportional to $S_{k-1}$ when $\left[s\left(x_{k}\right)-S_{k-1}\right] \leq 0$. Thus,

and

$$
w_{k}=\alpha S_{k-1} \quad \text { when }\left[s\left(x_{k}\right)-S_{k-1}\right] \quad \leq 0
$$

$$
w_{k}=\beta\left(1-S_{k-1}\right) \quad \text { when }\left[s\left(x_{k}\right)-S_{k-1}\right] \quad>0, \quad \text { where } 0 \leq \alpha, \beta \leq 1 \text {. }
$$

The model can thus be rewritten as:

$$
S_{k}=S_{k-1}+\alpha S_{k-1}\left[s\left(x_{k}\right)-S_{k-1}\right] \quad \text { when }\left[s\left(x_{k}\right)-S_{k-1}\right] \quad \leq 0
$$

and

$$
S_{k}=S_{k-1}+\beta\left(1-S_{k-1}\right)\left[s\left(x_{k}\right)-S_{k-1}\right] \quad \text { when }\left[s\left(x_{k}\right)-S_{k-1}\right] \quad>0
$$

$\alpha$ and $\beta$ represent the players' attitudes toward over- or under- predictions of audits, respectively, and we expect them to be affected by the nature of the audit schedule. Specifically, $\alpha$ and $\beta$ should be higher when the experienced variability is low, as in the Continuous treatment. That is, here players put more weight on the most recent evidence because less information is

\footnotetext{
11 This is similar to the reward prediction error models of learning (Schultz et al., 1997; Montague et al., 1996; Caplin and Dean, 2007). This model is also structurally similar to the EWA model of reinforcement learning investigated by March (1996) and Camerer and Ho (1999).
} 
needed to update beliefs. In contrast, in the intermittent treatments players should place more weight on the anchor $S_{k-1}$ than in the Continuous treatment because more information is needed to make an assessment. Figure 1 displays the outcomes of the simulations of these assumptions over 50 periods, with $\alpha=\beta=0.5$ in the Continuous treatment and $=0.2$ in the Intermittent 7 treatment. ${ }^{12}$ For the latter, we have arbitrarily averaged the outcomes of 30 random simulations. Figure 1 shows that our model predicts different patterns. In the Continuous treatment, the beliefs about the occurrence of an audit increase in the early periods. Then, they drop sharply almost immediately after audits stop. In the Intermittent 7 treatment, there is a constant pattern through period 22 after which there is a decreasing trend toward the end of the game. After the regime shift, the evolution of beliefs is smoother and beliefs are higher than in the Continuous treatment.

\section{[Insert Figure 1 about here]}

Based on this simple model, we derive the following hypotheses. ${ }^{13}$

Hypothesis 1. The pattern of belief updating differs across treatments. The occurrence of an audit in the previous period has a stronger influence on the evolution of beliefs in the Continuous treatment whereas the weight of the anchor is higher in the Intermittent treatment.

Hypothesis 2. In the Continuous treatment, beliefs on audits increase in the early periods and drop immediately after period 22 when audits actually stop.

Hypothesis 3. In the Intermittent 7 treatment, there is a constant pattern through period 22 after

\footnotetext{
12 We have also made simulations with $\alpha>\beta$ and $\alpha<\beta$ and with other values of $\alpha$ and $\beta$ to test the sensitivity of the model's predictions (available upon request). The predicted patterns of beliefs in the two treatments both before and after the regime shift are quite robust to these variations.

${ }^{13}$ We could consider alternatively a model in which individuals are able to recognize temporal patterns in the realization of audits, instead of assuming that individuals update their beliefs sequentially and do not recognize temporal patterns. In a companion paper (Hogarth and Villeval, 2014), we consider such an alternative model and show that it delivers qualitatively similar predictions although its complexity is dramatically higher.
} 
which there is a slowly decreasing trend toward period 50. Beliefs are higher than those in the Continuous treatment after the regime shift.

Hypothesis 4. The evolution of beliefs in the other Intermittent treatments follow the same pattern as in the Intermittent 7 treatment; the only difference is the mean level of the beliefs.

If we assume that group members are risk neutral and have the same prior beliefs and if we

consider the concept of payoff dominance, the following hypotheses can be made concerning

contribution behavior in the various treatments. ${ }^{14}$

Hypothesis 5. In the Continuous treatment, individuals contribute their whole endowment when they believe that the probability of being audited exceeds $40 \%$, and nothing otherwise. Before the regime shift, their contributions become increasingly full; after the regime shift, they free-ride.

Hypothesis 6. In the Intermittent treatment 7, individuals contribute their whole endowment if they believe that the probability of being audited exceeds $13 \%$, and nothing otherwise. Compared to the Continuous treatment, cooperation should be observed longer after the regime shift.

Hypothesis 7. Contributions in the Intermittent 5 and 3 treatments should follow the same pattern as in the Intermittent 7 treatment provided that participants believe that the probability of audit exceeds $13 \%$. Free-riding should develop much earlier in the Intermittent 7 Low Fine.

Risk, ambiguity, and loss aversion should all increase the predicted contributions in all treatments if individuals are more anxious about being sanctioned.

\subsection{Procedures}

The participants were 210 undergraduate students from local engineering and business schools who were invited via the ORSEE software (Greiner, 2004). 14 sessions were conducted at the GATE (Groupe d'Analyse et de Théorie Economique) research institute in Lyon, France. We ran four sessions of the Continuous treatment, four sessions of the Intermittent 7 treatment, and two

\footnotetext{
14 This game has also a number of mixed equilibria.
} 
sessions of each of the Intermittent 5, Intermittent 3 and Intermittent 7 Low Fine treatments. To check whether belief elicitation might affect contributions, beliefs about the occurrence of audits were elicited in half of the sessions with the Continuous and Intermittent 7 treatments. ${ }^{15}$ In all other sessions, beliefs were systematically elicited. Table 1 displays summary information.

\section{[Insert Table 1 about here]}

Upon arrival, participants were randomly assigned to a computer terminal by drawing a tag from an opaque bag. The instructions for each of the three parts of the experiment were distributed and read aloud after completion of the previous part (see Appendix B). Questions were answered in private. Participants' understanding was checked before the experiment started. At the end of the session, participants had to complete a final demographic questionnaire. A secretary who was not aware of the content of the experiment paid participants in cash and in private in a separate room; this information was made common in the instructions.

Sessions lasted approximately 60 minutes excluding payment. The average payment was $€ 16.89$ (standard deviation $€ 4.40$ ), including a $€ 4$ show-up fee and the earnings from either the risky or the ambiguous lottery task and from the loss aversion task.

\section{RESULTS}

We first analyze the evolution of beliefs over time before examining how contributions depend

15 Gächter and Renner (2010) suggest that eliciting incentivized beliefs increases contribution levels relative to a benchmark treatment without belief elicitation, while a contrary result is reported by Croson (2000). A difference is that in our design, we do not elicit beliefs about others' contributions but on the probability of being audited. 
on the audit regime. Last, we compare earnings in the various treatments.

\subsection{Beliefs}

Table 2 summarizes the mean beliefs by treatment, before and after audits are withdrawn. The two panels of Figure 2 display the relative frequencies of each belief in our main treatments (Continuous and Intermittent 7), before and after the regime shift. Finally, the two panels of Figure 3 display the evolution of beliefs over time in the various treatments.

\section{[Insert Table 2 and Figures 2 and 3 about here]}

Not surprisingly, Table 2 indicates that mean beliefs are higher in the Continuous than in the Intermittent 7 treatment in the first 22 periods. Interestingly, the opposite is true in periods $23-50$ although both treatments are now identical with respect to audits. Mann-Whitney tests (MW, hereafter) show that these differences are significant both in periods $1-22(p=0.001)$ and in periods $23-50(p=0.029) .{ }^{16}$ In the other treatments, beliefs differ significantly from those in the Continuous treatment in the first set of periods $(p=0.001$ in both Intermittent 5 and $3 ; p=0.003$ in Intermittent 7 Low Fine), but not in the second set ( $p=0.224,0.909$, and 0.138 , respectively).

The distributions of beliefs differ across treatments. ${ }^{17}$ In the Continuous treatment a majority of individuals underestimate the audit probability in the first set of periods (64\%) and, compared

\footnotetext{
${ }^{16}$ In all the non-parametric tests reported in this paper, the belief of a group of three members averaged across a block of periods (either periods 1-22 or periods 23-50) constitutes one unit of observation. Tests are two-tailed.

17 Kolmogorov-Smirnov tests (KS, hereafter) indicate that the distributions of beliefs in the Continuous and Intermittent 7 treatments differ significantly ( $p=0.002$ for periods $1-22, p=0.029$ for periods $23-50$ ). The comparison between the Continuous and the other treatments shows differences before the regime shift ( $p=0.006$ in Intermittent 5 , 0.001 in Intermittent 3, and 0.004 in Intermittent 7 Low Fine), but not after ( $p=0.461,0.979$, and 0.195 , respectively).
} 
to the Intermittent 7 treatment, a lower proportion of individuals overestimate the probability of an audit after period $22(59 \%)$. Indeed, in the Intermittent 7 treatment, a large majority of individuals overestimate the probability of an audit both before (71\%) and after the regime shift (84\%). In fact, Figure 2 shows three peaks in the distribution of beliefs in both treatments, at 0 , 50 and 100 . In periods $1-22$, these values represent respectively $9 \%, 26 \%$ and $36 \%$ of the observations in the Continuous treatment, and $10 \%, 35 \%$ and $10 \%$ of the observations in the Intermittent 7 treatment. In periods $23-50$, the corresponding percentages are $41 \%, 20 \%$ and $9 \%$ in the Continuous treatment and $16 \%, 32 \%$ and $6 \%$ in the Intermittent 7 treatment, despite the absence of an audit. The relatively high frequency of reports at 50 may be driven by risk aversion, since the use of the quadratic scoring rule makes it risky to report extreme values.

Figure 3a shows that the evolution of beliefs over time is consistent with the simulation of our model (Figure 1). Indeed, in the Continuous treatment beliefs increase progressively in the early periods and they decrease sharply immediately after the regime shift, without matching the actual probabilities. Then, they stabilize at a positive level through the last period, as some players still expect audits to happen. Wilcoxon tests show that beliefs differ before and after the regime shift $(p=0.004)$. In the Intermittent 7 treatment the pattern is different. Beliefs are relatively stable throughout the game with no visible shift when audits are withdrawn (Wilcoxon test: $p=0.475){ }^{18}$ Beliefs decrease smoothly after period 30 . This pattern looks similar in the other

\footnotetext{
${ }^{18}$ Figure 3 a shows a drop in mean beliefs in period 23. This can be explained by the fact that all groups were audited in
} 
treatments (see Figure 3b) but Wilcoxon tests show that beliefs differ before and after the regime shift ( $p=0.033$ in Intermittent 5 and 0.051 in Intermittent 3$)$, except in the Intermittent 7 Low Fine treatment $(p=0.110)$. Finally, beliefs are higher than 0 in the last period even though there was no audit in the previous 27 periods in both the Continuous (mean=22.3, $t$-test: $p=0.007$ ) and other treatments (corresponding values are 33.9 and $p<0.001$ in Intermittent 7; 35.6 and $p<0.001$ in Intermittent $5 ; 29.1$ and $p=0.005$ in Intermittent $3 ; 32.4$ and $p=0.001$ in Intermittent 7 Low Fine).

To test our model formally, Table 3 reports estimates of the determinants of beliefs from various Tobit models (since data are censored both on the left and the right). ${ }^{19}$ Robust standard errors are clustered at the group level. The first three models pool all treatments together and dummy variables for each treatment are included as independent variables, with the Continuous treatment taken as the reference. Model (1) considers periods 1-22 and model (2) periods 23-50; model (3) pools all the periods. Models (4) to (8) test our model for each treatment separately. The independent variables include the belief in $t-1$ (the anchor variable) and two variables that reflect reactions to prediction error in the previous period. The negative prediction error variable is defined as $S_{k-1}\left[s\left(x_{k}\right)-S_{k-1}\right]$ when no audit occurred in the previous period, and 0 otherwise. The positive prediction error variable is defined as $\left(1-S_{k-1}\right)\left[s\left(x_{k}\right)-S_{k-1}\right]$ when an audit occurred, and 0 otherwise. In all models we include a loss aversion variable, defined by the switching point in the

period 22 and by the so-called "bomb crater" effect (Guala and Mittone, 2005; Mittone, 2006). However, average beliefs increase again after period 23.

${ }^{19}$ OLS estimates offer similar qualitative results. 
loss aversion lottery. The risk aversion variable takes the value of the switching point in the risky lottery. The higher these values, the less loss or risk averse is the individual. The ambiguity aversion variable represents the difference in switching points in the risky and the ambiguous lotteries. A positive value means that the individual has switched from the lottery to the certain equivalent earlier in the ambiguous than in the risky decision task, thereby indicating ambiguity aversion. Finally, we control for gender and age, and include a time trend. ${ }^{20}$

\section{[Insert Table 3 about here]}

Table 3 confirms that, compared with the Continuous treatment, beliefs are significantly lower in all the intermittent treatments in the first set of periods (model (1)). In contrast, in the second set of periods (model (2)), they are significantly higher in the Intermittent 7 treatment albeit less so in the Intermittent 5 and Low Fine treatments. The coefficients of the Intermittent 7 variable do not differ significantly from those of the Intermittent 5 variable ( $p=0.760$ in periods $1-22$ and $p=0.453$ in periods $23-50$ ) or the Intermittent 7 Low Fine variable ( $p=0.885$ in periods $1-22$ and $p=0.489$ in periods 23-50). Reducing the frequency of audits from 7 to 5 or reducing the amount of the fine does not affect beliefs much in these regressions.

Models (4) to (8) support our theoretical prediction that when variability is low, more weight is put on the most recent evidence to form one's beliefs compared with the treatments with higher variability that require information from more past periods. Indeed, in the Continuous treatment,

\footnotetext{
${ }^{20}$ In other regressions, we included dummy variables for being punished in the previous period. Since the effect of punishment on beliefs was not significant, we do not report these regressions here.
} 
both negative (in periods 1-22) and positive (in periods 23-50) prediction errors in the most recent period affect beliefs significantly; both types of error have the same impact $(\alpha=\beta, p=0.152)$. In contrast, in most intermittent treatments only the anchor is significantly different from 0 while prediction errors in $t-1$ do not affect the current beliefs. A negative prediction error has a marginally significant impact only in the Intermittent 5 treatment (model (6)): overestimating the probability of an audit in $t-1$ reduces the belief at $t .{ }^{21}$ More ambiguity averse and older subjects assess the probability of an audit to be higher. Loss aversion does not influence beliefs, and risk attitudes are almost never significant.

We summarize our results on beliefs as follows.

Result 1. Prediction errors in the previous period influence belief formation in the Continuous treatment, while beliefs in the Intermittent treatments are strongly anchored on the previous beliefs that summarize the past history of the game. This supports Hypothesis 1 .

Result 2. In the Continuous treatment, assessments of the probability of an audit drop sharply immediately after the regime shift. This supports Hypothesis 2 .

Result 3. In contrast, beliefs in the Intermittent 7 treatment decrease slowly and smoothly after the regime shift; after audits are withdrawn, beliefs exceed those in the Continuous treatment through the end of the game. Reducing the frequency of audits to 5 or the amount of the fine has limited impact on beliefs. This supports both Hypotheses 3 and 4.

Result 4. In the Intermittent 7 treatment, the mean belief in the last period corresponds to the actual probability of audit before the regime shift.

\subsection{Contributions}

Table 2 summarizes the mean contributions by treatment both before and after audits are withdrawn. The two panels of Figure 4 display the evolution of contributions over time.

${ }^{21}$ In the regression the sign is positive but the variable is by construction negative. 


\section{[Insert Figure 4 about here]}

Table 2 reveals that in periods $1-22$ the mean contributions in the Continuous (15.3 ECU) and in the Intermittent 7 treatment (15.4 ECU) do not differ (MW: $p=0.573$ ); the distributions are also similar (KS: $p=0.319){ }^{22}$ Thus, although learning is imperfect, reducing the audit probability by two thirds and tripling the amount of the fine leads to similar high levels of cooperation. In contrast, while after period 22 the mean contribution decreases to 8.2 in the Continuous treatment, it remains high at 13.9 in the Intermittent 7 treatment. The differences in the means and distributions of contributions are highly significant (MW and KS: $p<0.001$ ). Reducing the number of audits from seven to five leaves the mean contribution unchanged (mean=14.9, $p=0.673$ before, and mean $=12.5, p=0.398$ after the shift). Reducing this number to three cannot sustain the same level of contribution (mean $=12.2, \mathrm{MW}: p=0.050$ before, and mean $=9.8, p=0.061$ after the shift); the same is true if the fine is reduced (mean=11.7, $p=0.034$ before, and mean=8.4, $p=0.007$ after the shift).

Figure 4a shows that contributions in the Continuous treatment increase regularly before the regime shift; afterwards, they decrease rapidly as beliefs of an audit drop, and free-riding develops as in a standard public goods game. In the $50^{\text {th }}$ period, the mean contribution is only 3.3 (S.D.=5.6), which almost corresponds to full free-riding. In contrast, in the Intermittent 7 treatment contributions are stable from the beginning of the game and only start to decrease after

\footnotetext{
22 No significant difference on average contribution was found between the Continuous treatments with and without belief elicitation. Therefore, we pool together the data from the Continuous treatments in this analysis. For the same reason we pool together all the data from the Intermittent 7 treatments with and without belief elicitation.
} 
period 36. Indeed, in the 50th period, the mean contribution is 10.3 (S.D.=7.9), which is significantly higher than in the Continuous treatment (MW: $p<0.001$ ). Figure $4 \mathrm{~b}$ shows that the patterns of contributions look similar in the Intermittent 7 and 5 treatments.

The contribution decision may involve beliefs about the occurrence of an audit as well as the willingness to cooperate with other group members conditional on their contributions. Table 4 reports the estimates of Tobit models with robust standard errors clustered at the group level. Models (1) to (3) concern periods 1-22 and models (4) to (6) periods 23-50. The independent variables include treatment dummies (with the Continuous treatment as the reference), the other group members' mean contribution in $t$-1 (which indicates the degree of group cooperation), the individual's attitudes towards losses, risk and uncertainty, gender, age, and finally, a time trend. In addition, we include either a dummy variable to control for a possible effect of belief elicitation on contributions in models (2) and (5) or the belief itself in models (3) and (6).

\section{[Insert Table 4 about here]}

Table 4 shows that contributions depend on three main elements. The first is the audit regime. In periods 1-22, there is no significant difference in the contribution level between the Intermittent 7 and 5 treatments, on the one hand, and the Continuous treatment, on the other. In contrast, in periods 23-50 the contribution is higher in the Intermittent 7 and 5 treatments than in the Continuous treatment. This is also true for the Intermittent 3 treatment after the regime shift and before we control for beliefs (however, contributions are lower in the Intermittent 3 and Intermittent 7 Low Fine treatment in periods 1-22). Second, the higher the expected probability 
of being audited, the greater the contributions. Third, as in standard public goods games, cooperation is conditional: the more group members cooperate, more is contributed. We suspect that the associated coefficient is high because the norm of matching the mean contribution of others is stated explicitly and because the deviation from this mean contribution determines the level of the fine. Models (4) and (5) show that less risk averse individuals contribute less but, when controlling for beliefs, this effect vanishes. Ambiguity aversion is marginally significant, even after controlling for beliefs (model (6)). Finally, a negative time trend is identified after the regime shift.

To assess how contributions adjust to changes in expectations in the various treatments, Table 5 reports the estimates of Tobit models in which the dependent variable is the evolution of the contribution between $t-1$ and $t$. Model (1) concerns periods 1-22, model (2) periods 23-50, and model (3) pools all the periods together. The independent variables include the variation of beliefs between $t$-1 and $t$, interacted with each intermittent treatment. We also include a punishment variable, interacted with each intermittent treatment. In fact, although this variable did not affect beliefs, it might influence the evolution of contributions. We also control for the mean contribution of the other group members in $t$ - 1 , for individual characteristics, and for time.

\section{[Insert Table 5 about here]}

The three models in Table 5 show that contributions increase between two periods in reaction to an increase in the belief of being audited. There is a large additional impact of the variation of beliefs in the intermittent treatments but only in periods 1-22 (and marginal in the 
Intermittent 5 treatment, $p=0.111$ ). This additional impact is not only due to the perspective of a higher fine in case of a lower than average contribution since it is also significant in the Intermittent 7 with Low Fine. In periods 23-50, the evolution of beliefs has the same effect on contributions across treatments but since beliefs react less to immediate prediction errors in the intermittent treatments, contributions decrease less in the Intermittent than in the Continuous treatment. Being punished in $t$-1 motivates individuals to raise their contribution, especially in the Intermittent 5 treatment. Finally, we find evidence of conditional cooperation.

We summarize our main results on contributions as follows.

Result 5. In the Continuous treatment, players progressively coordinate on a high contribution level before the regime shift. After the regime shift they rapidly engage in free-riding. This behavior is consistent with rapid changes in beliefs. These outcomes support Hypothesis 5 .

Result 6. In the Intermittent 7 treatment, individuals contribute as much as in the Continuous treatment before the regime shift. After the shift, cooperation remains higher than in the Continuous treatment, due to a stronger anchoring of beliefs and a lower reaction to current prediction errors. This supports Hypothesis 6.

Result 7. Reducing the frequency of audits from 7 to 5 affects neither beliefs nor contributions. Reducing the frequency of audits further or reducing the amount of the fine, lowers contributions. This supports Hypothesis 7.

\subsection{Efficiency}

Table 2 summarizes mean payoffs (net earnings) per period before the regime shift, after the regime shift and for all periods, by treatment. It shows that differences in payoffs between treatments emerge after audits have been withdrawn. In the Intermittent 7 and 5 treatments, earnings increase after the regime shift as group members still cooperate but no longer pay fines. 
In contrast, in the Continuous treatment payoffs decrease because free-riding develops rapidly. Mean payoffs in the Intermittent 7 and 5 treatments are higher than in the Continuous treatment in periods 23-50 (MW: $p<0.001$ and 0.014, respectively). When all periods are considered, payoffs are higher only in the Intermittent 7 treatment $(p=0.030)$. Reducing the amount of the fine does not maintain the beneficial impact of intermittent audits. This supports our last result. ${ }^{23}$ Result 8: Under ambiguity, the use of an intermittent audit scheme increases efficiency. However, the frequency of audits and the level of fines must be high enough to produce this efficiency gain.

\section{DISCUSSION AND CONCLUSION}

We provide the first systematic evidence comparing the effects of continuous and intermittent audit schemes on the enforcement of cooperation in the provision of public goods under ambiguity on the audit regime. We show that under ambiguity, an intermittent pattern of audits can be as effective in supporting cooperation as continuous monitoring of behavior, provided sanctions are sufficiently high. Moreover, if audits are withdrawn, an intermittent scheme maintains cooperation much longer than its continuous counterpart. We therefore find efficiency gains for intermittent relative to continuous audits, a result that is even stronger if we consider that costs of intermittent audits are presumably lower.

The basis for an economic explanation can be traced to the relative difficulty individuals experience in updating their beliefs. Our anchor-and-adjustment model shows that when audits

\footnotetext{
${ }^{23}$ We acknowledge that using earnings as a measure of efficiency disregards the welfare losses for individuals who dislike uncertainty and suffer from this situation.
} 
are irregular, players need to ground their beliefs on a longer sequence of events. As a consequence, prediction errors in the most recent periods are less informative. Thus, since beliefs are updated more slowly, players continue to cooperate longer. And since cooperation is conditional, efficiency remains high.

The main implication of our research is that in the presence of ambiguity, policies that involve irregular audits can be more effective than policies that involve audits on a continuous basis (like screening passengers at airports or using video cameras in streets), provided that the level of sanctions is sufficiently high. These are clearly important guidelines for policymakers who have to optimize the use of resources in monitoring behavior in areas such as tax collection, and financial regulation as well as the management of public services that involve policing. In the presence of ambiguity, another advantage of intermittent audits is that the threat of auditing persists even when audits have been removed. This suggests that restrictions in auditing budgets in time of crisis do not necessarily lead to an explosion of fraud since individuals do not realize immediately that a regime shift has occurred. Our results suggest that policy makers could plan periods during which audits are or are not going to take place.

An interesting extension would be to test the optimal duration of sequences with and without audits. We could also study how contributions are affected by reintroducing a sequence with intermittent or continuous audits after a sequence with no audits. Moreover, some regulations impose an audit to be done periodically, say, every five years. We could examine whether on 
average one audit every five years provides less of a deterrent than one audit in exactly five-year intervals or one audit within every five years. Finally, reversing our design (moving from a no-audit regime to a continuous or irregular audit regime) would also be informative. It is likely that the introduction of a continuous audit regime would lead to higher contributions compared to an intermittent audit regime. Testing this hypothesis would help to characterize more fully the conditions under which continuous or intermittent auditing schemes are optimal in the presence of regime changes.

\section{REFERENCES}

Alm, J., Jackson, B., \& McKee, M. (1992). Institutional uncertainty and taxpayer compliance. The American Economic Review, 82(4), 1018-1026.

Andreoni, J. (1988). Why free ride? Strategies and learning in public goods experiments. Journal of Public Economics 37(3), 291-304.

Baker, T., Harel, A. and Kugler, T. (2004). The Virtues of Uncertainty in Law: An Experimental Approach. Iowa Law Review 89, 1-43.

Bebchuk, L.A., Kaplow, L. (1992). Optimal Sanctions When Individuals are Imperfectly Informed About the Probability of Apprehension. The Journal of Legal Studies 21(2), 365-370.

Bereby-Meyer, Y., Roth, A. (2006). The speed of learning in noisy games: Partial reinforcement and the sustainability of cooperation, American Economic Review 96, 1029-1042.

Blanco, M., Engelmann, D., Koch, A., Normann, H.T. (2010). Belief elicitation in experiments: is there a hedging problem? Experimental Economics 13(4), 412-438.

Bochet, O., Page, T., Putterman, L. (2006). Communication and punishment in voluntary contribution experiments. Journal of Economic Behavior \& Organization 60(1), 11-26.

Camerer, C.F., Ho, T.H. (1999). Experience-weighted Attraction Learning in Normal Form Games. Econometrica 67(4), 827-874.

Caplin, A., Dean, M. (2007). The Neuroeconomic Theory of Learning. American Economic Review 97(2), 148-152. 
Carpenter, J. (2007). Punishing free-riders: how group size affects mutual monitoring and the provision of public goods. Games and Economic Behavior 60(1), 31-51.

Croson, R.T.A. (2000). Thinking like a game theorist: factors affecting the frequency of equilibrium play. Journal of Economic Behavior \& Organization 41(3), 299-314.

deAngelo, G.J., Charness, G. (2012). Deterrence, Expected Cost, Uncertainty and Voting: Experimental Evidence. Journal of Risk and Uncertainty 44, 73-100.

Denant-Boemont, L., Masclet, D., Noussair, C. (2007). Punishment, counterpunishment and sanction enforcement in a social dilemma experiment. Economic Theory 33(1), 145-167.

Eeckhout, J., Persico, N., Todd, P.E. (2010). A theory of optimal random crackdowns. American Economic Review 100, 1104-1135.

Egas, M., Riedl, A. (2008). The economics of altruistic punishment and the maintenance of cooperation. Proceedings of the Royal Society B: Biological Sciences 275(1637), 871-878.

Ellsberg, Daniel. "Risk, ambiguity, and the Savage axioms." The Quarterly Journal of Economics (1961): 643-669.

Falkinger, J. (1996). Efficient Private Provision of Public Goods by Rewarding Deviations from Average. Journal of Public Economics 62(3), 413-422.

Falkinger, J., Fehr, E., Gächter, S., Winter-Ebmer, R. (2000). A Simple Mechanism for the Efficient Provision of Public Goods: Experimental Evidence. American Economic Review 90(1), 247-264.

Fehr, E., Gächter, S. (2000). Cooperation and punishment in public goods experiments. American Economic Review 90(4), 980-994.

Fehr, E., Rockenbach, B. (2003). Detrimental effects of sanctions on human altruism. Nature 422, 137-140.

Ferster, C. S., and Skinner, B. F. (1957). Schedules of Reinforcement. New York, NY: Appleton-Century-Crofts.

Fox, C.R., Tversky, A. (1995). Ambiguity Aversion and Comparative Ignorance. The Quarterly Journal of Economics 110(3), 583-603.

Friedland N. (1982). A note on tax evasion as a function of the quality of information about the magnitude and credibility of threatened fines: some preliminary research. Journal of Applied Social Psychology 12(1), 54-59.

Gächter, S., Elke R. (2010). The effects of (incentivized) belief elicitation in public goods experiments. Experimental Economics 13(3), 364-377.

Gilboa, I., Postlewaite, A. W., Schmeidler, D. (2008). Probability and uncertainty in economic modeling. Journal of Economic Perspectives 22(3), 173-188.

Guala, F., Mittone, L. (2005). Experiments in economics: External validity and the robustness of phenomena. Journal of Economic Methodology 12 (4), 495-515.

Harel, A., Segal, U. (1999). Criminal Law and Behavioral Law and Economics: Observations on the Neglected Role of Uncertainty in Deterring Crime. American Law and Economics Review 1, 276-312. 
Hilgard, E. R., Bower, G.H. (1975) Theories of Learning, $4^{\text {th }}$ ed, Englewood Clisffs, HJ: Prentice-Hall.

Hogarth, M. R., Villeval, M.C. (2014). Intermittent incentives and the persistence of effort: Experimental evidence. SSRN. http://ssrn.com/abstract=1655110

Hogarth, R. M., Einhorn, H. J. (1992). Order Effects in Belief Updating: The Belief-Adjustment Model. Cognitive Psychology 24, 1-55.

Houser, D., Xiao, E., McCabe, K., Smith, V. (2008). When punishment fails: Research on sanctions, intentions and non-cooperation. Games and Economic Behavior 62, 509-532.

Isaac, R.M., McCue, K.F., Plott, C.R. (1985). Public goods provision in an experimental environment, Journal of Public Economics 26(1), 51-74.

Kastlunger, B., Kirchler, E., Mittone, L., Pitters, J. (2009). Sequences of audits, tax compliance, and taxpaying strategies. Journal of Economic Psychology 30, 405-418.

Lazear E.P. (2006). Speeding, terrorism, and teaching. The Quarterly Journal of Economics 121(3), 1029-1061.

Ledyard, O. (1995). Public goods: some experimental results. In J. Kagel and A. Roth (Eds.), Handbook of experimental economics. Princeton: Princeton University Press (Chap. 2).

Maciejovsky, B., Kirchler, E., Schwarzenberger, H. (2007). Misperception of chance and loss repair: On the dynamics of tax compliance. Journal of Economic Psychology 28(6), 678-691.

Manski, C. (2004). Measuring Expectations. Econometrica 72(5), 1329-1376.

March, J. G. (1996). Learning to be risk averse. Psychological Review, 103(2), 309-319

Marwell, G., Ames, R.E. (1981). Economists free ride, does anyone else? Experiments on the provision of public goods, IV. Journal of Public Economics 15(3), 295-310.

Masclet, D., Noussair, C., Villeval, M., Tucker, S. (2003). Monetary and nonmonetary punishment in the voluntary contributions mechanism. American Economic Review 93(1), 366-380.

Mittone, L. (2006). Dynamic behaviour in tax evasion: An experimental approach. The Journal of Socio-Economics 35 (5), 813-835.

Muehlbacher, S., Mittone, L., Kastlunger, B., Kirchler, E. (2012). Uncertainty resolution in tax experiments: Why waiting for an audit increases compliance. The Journal of Socio-Economics 41, 289-291.

Montague, P.R., Dayan, P., Sejnowski, T.J. (1996). A framework for mesencephalic dopamine systems based on predictive Hebbian learning. Journal of Neurosciences 16, 1936-1947.

Nikiforakis, N. (2008). Punishment and counter-punishment in public good games: Can we really govern ourselves? Journal of Public Economics 92 (1-2), 91-112.

Nyarko, Y., Schotter, A. (2002). An Experimental Study of Belief Learning Using Elicited Beliefs. Econometrica 70 (3), 971-1005.

Polinsky, A.M., Shavell, S. (2000). The Economic Theory of Public Enforcement of Law. Journal of Economic Literature 38, 45-76. 
Ross, H.L. (1984). Deterring the Drinking Driver: Legal Policy and social control. Lexington, MA: Lexington Books.

Samuelson, P. (1954) The pure theory of public expenditure. Review of Economics and Statistics 36, 387-389.

Schultz, W., Apicella, P., Ljungberg, T. (1993). Responses of monkey dopamine neurons to reward and conditioned stimuli during successive steps of learning a delayed response task. Journal of Neurosciences 13, 900-913.

Snow, A., Warren, R.S. Jr. (2005a). Ambiguity about Audit Probability, Tax Compliance, and Taxpayer Welfare. Economic Inquiry 43 (4), 865-871.

Snow, A., Warren, R.S. Jr. (2005b). Tax evasion under random audits with uncertain detection. Economics Letters 88(1), 97-100.

Snow, A., Warren, R.S. Jr. (2007). Audit Uncertainty, Bayesian Updating, and Tax Evasion. Public Finance Review 35(5), 555-571.

Spicer, M.W., Thomas, J.E. (1982). Audit probabilities and tax evasion decision: an experimental approach. Journal of Economic Psychology 2(3), 241-245.

Tan, F., Yim, A. (2013). Can strategic uncertainty help deter tax evasion? An experiment on auditing rules. Journal of Economic Psychology, http://dx.doi.org/10.1016/j.joep.2012.11.005.

Tyran, J.R., Feld L. P. 2006. Achieving Compliance when Legal Sanctions are Non Deterrent. Scandinavian Journal of Economics 108(1), 135-156.

Wang, S. W. (2011). Incentive effects: The case of belief elicitation from individuals in groups. Economics Letters 111(1), 30-33. 


\section{TABLES AND FIGURES}

Table 1. Summary of the experimental sessions

\begin{tabular}{clcccc}
\hline $\begin{array}{c}\text { Session } \\
\text { number }\end{array}$ & Treatment & $\begin{array}{c}\text { Number of } \\
\text { audits }\end{array}$ & $\begin{array}{c}\text { Fine } \\
\text { coefficient }\end{array}$ & $\begin{array}{c}\text { Belief } \\
\text { elicitation }\end{array}$ & $\begin{array}{c}\text { Number of } \\
\text { participants }\end{array}$ \\
\hline 1 & Continuous & 22 & 1.25 & No & 18 \\
2 & Intermittent 7 & 7 & 3.75 & No & 15 \\
3 & Continuous & 22 & 1.25 & No & 12 \\
4 & Intermittent 7 & 7 & 3.75 & No & 15 \\
5 & Continuous & 22 & 1.25 & Yes & 15 \\
6 & Continuous & 22 & 1.25 & Yes & 18 \\
7 & Intermittent 7 & 7 & 3.75 & Yes & 15 \\
8 & Intermittent 7 & 7 & 3.75 & Yes & 15 \\
9 & Intermittent 5 & 5 & 3.75 & Yes & 15 \\
10 & Intermittent 5 & 5 & 3.75 & Yes & 18 \\
11 & Intermittent 3 & 3 & 3.75 & Yes & 18 \\
12 & Intermittent 7 & 7 & 1.25 & Yes & 15 \\
& with low fine & & & & \\
13 & Intermittent 3 & 3 & 3.75 & Yes & 9 \\
14 & Intermittent 7 & 7 & 1.25 & Yes & 12 \\
& with low fine & & & & \\
\hline
\end{tabular}


Table 2. Summary statistics

\begin{tabular}{|c|c|c|c|c|c|c|}
\hline Treatments & Periods & Continuous & $\begin{array}{c}\text { Intermittent } \\
7 \\
\end{array}$ & $\begin{array}{c}\text { Intermittent } \\
5 \\
\end{array}$ & $\begin{array}{c}\text { Intermittent } \\
3 \\
\end{array}$ & $\begin{array}{c}\text { Intermittent } \\
7 \text { low fine }\end{array}$ \\
\hline \multirow{3}{*}{ Beliefs (0-100) } & $1-22$ & $68(33)$ & $47.6(28.6)$ & $48.4(26.4)$ & $42.6(33.1)$ & $49.7(29.7)$ \\
\hline & $23-50$ & $31.6(34.4)$ & $44.5(29.7)$ & $41.3(29.0)$ & $30.3(34.0)$ & $41.3(33.2)$ \\
\hline & All & $47.3(38.0)$ & $45.8(29.3)$ & $44.4(28.1)$ & $35.7(34.1)$ & $45.0(32.0)$ \\
\hline \multirow{3}{*}{ Contributions } & $1-22$ & $15.3(5.3)$ & $15.4(5.7)$ & $14.9(5.4)$ & $12.2(6.1)$ & $11.7(6.6)$ \\
\hline & $23-50$ & $8.2(7.4)$ & $13.9(6.5)$ & $12.5(6.7)$ & $9.8(6.3)$ & $8.4(6.9)$ \\
\hline & All & $11.3(7.4)$ & $14.6(6.2)$ & $13.5(6.3)$ & $10.8(6.3)$ & $9.9(6.9)$ \\
\hline \multirow{4}{*}{$\begin{array}{l}\text { Negative } \\
\text { deviation from } \\
\text { average } \\
\left(c_{i}-\bar{C}\right) \text { if } c_{i}<\bar{C}\end{array}$} & $1-22$ & $-4.3(3.8)$ & $-5.3(4.9)$ & $-4.9(4.3)$ & $-5.5(4.9)$ & $-6.2(4.6)$ \\
\hline & $23-50$ & $-5.7(4.6)$ & $-5.3(4.9)$ & $-5.0(4.6)$ & $-4.5(3.6)$ & $-5.8(4.5)$ \\
\hline & All & $-5.2(4.4)$ & $-5.3(4.9)$ & $-5.0(4.5)$ & $-4.9(4.2)$ & $-6.0(4.6)$ \\
\hline & & & & & & \\
\hline \multirow{3}{*}{ Payoffs } & $1-22$ & $25.9(3.8)$ & $25.1(9.1)$ & $25.6(7.7)$ & $25.0(6.9)$ & $24.8(5.2)$ \\
\hline & $23-50$ & $24.1(5.3)$ & $27.0(4.6)$ & $26.2(4.7)$ & $24.9(4.4)$ & $24.2(5.2)$ \\
\hline & All & $24.9(4.8)$ & $26.1(7.0)$ & $26.0(6.2)$ & $24.9(5.6)$ & $24.5(5.2)$ \\
\hline \multicolumn{2}{|c|}{ Number of observations } & 3,150 & 3,000 & 1,650 & 1,350 & 1,350 \\
\hline
\end{tabular}

Note: Numbers indicate mean values and standard deviations are in parentheses. 
Table 3. Determinants of beliefs (Tobit models with robust standard errors clustered at the group level)

\begin{tabular}{|c|c|c|c|c|c|c|c|c|}
\hline $\begin{array}{l}\text { Dependent variable: } \\
\text { Beliefs }\end{array}$ & $\begin{array}{l}\text { Periods } 1-22 \\
\text { (1) }\end{array}$ & $\begin{array}{c}\text { Periods } 23-50 \\
\text { (2) }\end{array}$ & $\begin{array}{c}\text { All periods } \\
\text { (3) }\end{array}$ & $\begin{array}{c}\text { Continuous } \\
\text { (4) }\end{array}$ & $\begin{array}{l}\text { Intermit. } 7 \\
(5)\end{array}$ & $\begin{array}{c}\text { Intermit. } 5 \\
\text { (6) }\end{array}$ & $\begin{array}{c}\text { Intermit. } 3 \\
(7)\end{array}$ & $\begin{array}{l}\text { Intermit. } 7 \\
\text { low fine (8) }\end{array}$ \\
\hline Intermittent 7 & $\begin{array}{c}-25.99 * * * \\
(6.43)\end{array}$ & $\begin{array}{l}21.99 * * \\
(8.77)\end{array}$ & $\begin{array}{c}0.15 \\
(4.22)\end{array}$ & - & - & - & - & - \\
\hline Intermittent 5 & $\begin{array}{c}-24.23 * * * \\
(6.43)\end{array}$ & $\begin{array}{l}16.97 * \\
(10.22)\end{array}$ & $\begin{array}{l}-1.87 \\
(6.01)\end{array}$ & - & - & - & - & - \\
\hline Intermittent 3 & $\begin{array}{c}-35.50 * * * \\
(6.43)\end{array}$ & $\begin{array}{l}-1.23 \\
(9.38)\end{array}$ & $\begin{array}{c}-17.15 * * * \\
(5.09)\end{array}$ & - & - & - & - & - \\
\hline $\begin{array}{l}\text { Intermittent } 7 \\
\text { with low fine }\end{array}$ & $\begin{array}{c}-25.00 * * * \\
(7.43)\end{array}$ & $\begin{array}{c}17.06^{\#} \\
(10.77)\end{array}$ & $\begin{array}{l}-2.19 \\
(6.49)\end{array}$ & - & - & - & - & - \\
\hline Anchor & - & - & - & $\begin{array}{c}1.56 * * * \\
(0.20)\end{array}$ & $\begin{array}{c}0.69 * * * \\
(0.18)\end{array}$ & $\begin{array}{c}0.88 * * * \\
(0.20)\end{array}$ & $\begin{array}{c}1.13 * * * \\
(0.17)\end{array}$ & $\begin{array}{c}0.66 * * * \\
(0.13)\end{array}$ \\
\hline $\begin{array}{l}\text { Negative prediction } \\
\text { error (alpha) }\end{array}$ & - & - & - & $\begin{array}{c}<0.01 * * * \\
(<0.01)\end{array}$ & $\begin{array}{c}<0.01 \\
(<0.01)\end{array}$ & $\begin{array}{l}<0.01 * \\
(<0.01)\end{array}$ & $\begin{array}{c}<0.01 \\
(<0.01)\end{array}$ & $\begin{array}{c}<0.01 \\
(<0.01)\end{array}$ \\
\hline $\begin{array}{l}\text { Positive prediction } \\
\text { error (beta) }\end{array}$ & - & - & - & $\begin{array}{l}0.01 * * * \\
(<0.01)\end{array}$ & $\begin{array}{c}<0.01 \\
(<0.01)\end{array}$ & $\begin{array}{c}<0.01 \\
(<0.01)\end{array}$ & $\begin{array}{c}<0.01 \\
(<0.01)\end{array}$ & $\begin{array}{c}<0.01 \\
(<0.01)\end{array}$ \\
\hline Loss aversion & $\begin{array}{l}-0.20 \\
(1.94)\end{array}$ & $\begin{array}{l}-0.93 \\
(2.60)\end{array}$ & $\begin{array}{l}-0.62 \\
(1.94)\end{array}$ & $\begin{array}{c}1.50 \\
(1.12)\end{array}$ & $\begin{array}{l}-1.87 \\
(2.32)\end{array}$ & $\begin{array}{l}-1.42 \\
(1.92)\end{array}$ & $\begin{array}{c}2.83 \\
(2.66)\end{array}$ & $\begin{array}{l}-1.29 \\
(1.49)\end{array}$ \\
\hline Risk index & $\begin{array}{c}0.60 \\
(0.77)\end{array}$ & $\begin{array}{l}-1.18 \\
(1.30)\end{array}$ & $\begin{array}{l}-0.37 \\
(0.82)\end{array}$ & $\begin{array}{l}-0.73 \\
(0.49)\end{array}$ & $\begin{array}{c}-0.79 * * \\
(0.36)\end{array}$ & $\begin{array}{l}-0.62 \\
(0.60)\end{array}$ & $\begin{array}{l}1.02 * \\
(0.58)\end{array}$ & $\begin{array}{l}-0.37 \\
(1.60)\end{array}$ \\
\hline Ambiguity aversion & $\begin{array}{c}1.08 * * \\
(0.54)\end{array}$ & $\begin{array}{c}1.25 \\
(0.90)\end{array}$ & $\begin{array}{c}1.19 * * \\
(0.53)\end{array}$ & $\begin{array}{c}0.10 \\
(0.53)\end{array}$ & $\begin{array}{c}1.00 * * \\
(0.41)\end{array}$ & $\begin{array}{l}1.02 * \\
(0.57)\end{array}$ & $\begin{array}{c}0.96 \\
(1.10)\end{array}$ & $\begin{array}{l}-0.46 \\
(0.62)\end{array}$ \\
\hline Male & $\begin{array}{l}-5.20 \\
(3.79)\end{array}$ & $\begin{array}{c}0.28 \\
(5.23)\end{array}$ & $\begin{array}{l}-2.30 \\
(3.52)\end{array}$ & $\begin{array}{l}-0.55 \\
(3.29)\end{array}$ & $\begin{array}{l}-2.33 \\
(3.85)\end{array}$ & $\begin{array}{c}2.24 \\
(4.04)\end{array}$ & $\begin{array}{c}-11.25^{* *} \\
(4.52)\end{array}$ & $\begin{array}{l}-4.19^{\#} \\
(2.69)\end{array}$ \\
\hline Age & $\begin{array}{c}1.45 * * * \\
(0.46)\end{array}$ & $\begin{array}{c}1.82 * * * \\
(0.69)\end{array}$ & $\begin{array}{c}1.67 * * * \\
(0.57)\end{array}$ & $\begin{array}{l}2.14^{*} \\
(1.18)\end{array}$ & $\begin{array}{c}0.49 * * * \\
(0.19)\end{array}$ & $\begin{array}{c}1.31 * * * \\
(0.49)\end{array}$ & $\begin{array}{l}0.77 * \\
(0.43)\end{array}$ & $\begin{array}{l}-0.07 \\
(0.29)\end{array}$ \\
\hline Period & $0.43 *$ & $-0.80 * * *$ & $-0.68 * * *$ & $0.37 * * *$ & -0.15 & $-0.12 *$ & $-0.26^{* * *}$ & $-0.29 * * *$ \\
\hline
\end{tabular}




\begin{tabular}{lcccccccc}
\hline & $(0.25)$ & $(0.17)$ & $(0.14)$ & $(0.10)$ & $(0.11)$ & $(0.07)$ & $(0.10)$ & $(0.07)$ \\
Constant & $32.51^{* *}$ & 24.53 & $31.46^{* * *}$ & $-85.68^{* * *}$ & $24.31^{* * *}$ & -5.58 & $-30.82^{*}$ & $32.62^{* *}$ \\
& $(15.07)$ & $(25.43)$ & $(19.12)$ & $(29.43)$ & $(9.04)$ & $(12.10)$ & $(17.04)$ & $(15.52)$ \\
\hline Obs.- Left/right cens. & $3,300-385 / 502$ & $4,200-1,067 / 318$ & $7,500-1,452 / 820$ & $1,617-433 / 344$ & $1,470-198 / 113$ & $1,617-257 / 104$ & $1,323-349 / 120$ & $1,323-197 / 133$ \\
Log-pseudo-likelihood & $-13,203.27$ & $-15,991.38$ & $-29,431.89$ & $-4,729.16$ & $-5,924.01$ & $-6,277.45$ & $-4,599.19$ & $-5,141.38$ \\
Pseudo R & 0.02 & 0.01 & 0.01 & 0.14 & 0.04 & 0.06 & 0.08 & 0.06 \\
\hline
\end{tabular}

Note: In models (1) to (3), the Continuous treatment is the omitted reference category. Robust standard errors are in parentheses, clustered by group. The data include only the sessions with belief elicitation. ${ }^{* * *} p<0.01,{ }^{* *} p<0.05, * p<0.1,{ }^{\#} \mathrm{p}<0.12$. 
Table 4. Determinants of contributions (Tobit models with robust standard errors clustered at the group level)

\begin{tabular}{|c|c|c|c|c|c|c|}
\hline \multirow{2}{*}{$\begin{array}{l}\text { Dependent variable: } \\
\text { Contribution }\end{array}$} & \multicolumn{3}{|c|}{ Periods $1-22$} & \multicolumn{3}{|c|}{ Periods $23-50$} \\
\hline & $(1)$ & $(2)$ & (3) & (4) & $(5)$ & (6) \\
\hline Intermittent 7 & $-0.23(0.96)$ & $-0.24(0.96)$ & $0.02(1.00)$ & $3.37 * * *(0.77)$ & $3.37 * * *(0.77)$ & $3.11 * * *(0.83)$ \\
\hline Intermittent 5 & $-0.52(1.11)$ & $-0.28(1.19)$ & $-0.88(1.15)$ & $3.03 * * *(0.98)$ & $3.21 * * *(1.05)$ & $2.06^{* *}(1.03)$ \\
\hline Intermittent 3 & $-2.24 * * *(0.84)$ & $-2.00 * *(0.92)$ & $-2.40 * * *(0.84)$ & $1.40 * *(0.69)$ & $1.58 * *(0.79)$ & $0.92(0.70)$ \\
\hline Intermittent 7 low fine & $-2.71 * * *(0.89)$ & $-2.47 * *(0.98)$ & $-3.05 * * *(0.87)$ & $0.90(0.83)$ & $1.08(0.91)$ & $-0.09(0.77)$ \\
\hline Belief elicitation & - & $-0.52(1.01)$ & - & - & $-0.39(0.83)$ & \\
\hline Belief & - & - & $0.02 * * *(0.01)$ & - & - & $0.04 * * *(0.01)$ \\
\hline $\begin{array}{l}\text { Others' mean } \\
\text { contribution in } t-1\end{array}$ & $0.89 * * *(0.08)$ & $0.88 * * *(0.08)$ & $0.89 * * *(0.08)$ & $0.90 * * *(0.07)$ & $0.90 * * *(0.07)$ & $0.90 * * *(0.07)$ \\
\hline Loss aversion & $0.08(0.33)$ & $0.08(0.32)$ & $0.06(0.33)$ & $0.01(0.31)$ & $0.01(0.31)$ & $0.01(0.31)$ \\
\hline Risk index & $-0.08(0.15)$ & $-0.08(0.15)$ & $-0.10(0.15)$ & $-0.15 *(0.09)$ & $-0.15 *(0.09)$ & $-0.14(0.10)$ \\
\hline Ambiguity aversion & $0.12(0.13)$ & $0.11(0.13)$ & $0.12(0.12)$ & $0.24^{\#}(0.15)$ & $0.23(0.15)$ & $0.24^{\#}(0.15)$ \\
\hline Male & $0.26(0.70)$ & $0.25(0.70)$ & $0.32(0.71)$ & $0.27(0.69)$ & $0.27(0.69)$ & $0.30(0.71)$ \\
\hline Age & $-0.02(0.03)$ & $-0.03(0.04)$ & $-0.03(0.03)$ & $-0.03(0.03)$ & $-0.04(0.03)$ & $-0.05(0.04)$ \\
\hline Period & $-0.02(0.02)$ & $-0.02(0.02)$ & $-0.02(0.02)$ & $-0.12 * * *(0.02)$ & $-0.12 * * *(0.02)$ & $-0.10 * * *(0.02)$ \\
\hline Constant & $5.20 * *(2.58)$ & $5.58 * *(2.74)$ & $4.73 *(2.52)$ & $5.84 * * *(2.02)$ & $6.12 * * *(2.15)$ & $4.91 * *(2.04)$ \\
\hline Observations & 4,410 & 4,410 & 4,410 & 5,880 & 5,880 & 5,880 \\
\hline Left/right-censored o. & $254 / 1,388$ & $254 / 1,388$ & $254 / 1,388$ & $1,009 / 1,138$ & $1,009 / 1,138$ & $1,009 / 1,138$ \\
\hline Log-pseudo-likelihood & $-10,687.71$ & $-10,686.25$ & $-10,663.04$ & $-14,967.75$ & $-14,966.88$ & $-14,911.45$ \\
\hline Pseudo $\mathrm{R}^{2}$ & 0.07 & 0.07 & 0.07 & 0.09 & 0.09 & 0.09 \\
\hline
\end{tabular}

Note: The Continuous treatment is the omitted reference category. Robust standard errors are in parentheses, clustered by group. All sessions included.

$* * * p<0.01, * * p<0.05, * p<0.1,{ }^{*} p<0.12$. 
Table 5. Determinants of the evolution of contribution between $t$ - 1 and $t$ (OLS models with robust standard errors clustered at the group level)

\begin{tabular}{|c|c|c|c|}
\hline Evolution of contribution between $t-1$ and $t$ & $\begin{array}{c}\text { Periods } 1-22 \\
\text { (1) } \\
\end{array}$ & $\begin{array}{c}\text { Periods } 23-50 \\
(2) \\
\end{array}$ & $\begin{array}{c}\text { All periods } \\
(3)\end{array}$ \\
\hline Evolution of beliefs between $t-1$ and $t$ & $0.03 * *(0.01)$ & $0.06 * * *(0.02)$ & $0.05 * * *(0.02)$ \\
\hline Evolution of belief $*$ Intermittent 7 & $0.04 * * *(0.02)$ & $<0.01(0.03)$ & $0.02(0.02)$ \\
\hline Evolution of belief $*$ Intermittent 5 & $0.04^{\#}(0.02)$ & $<0.01(0.03)$ & $0.02(0.02)$ \\
\hline Evolution of belief $*$ Intermittent 3 & $0.05 *(0.03)$ & $0.03(0.03)$ & $0.03(0.02)$ \\
\hline Evolution of belief * Intermittent 7 with low fine & $0.03^{* *}(0.01)$ & $0.01(0.03)$ & $0.02(0.02)$ \\
\hline Punished in $t-1$ & $2.86^{* * *}(0.23)$ & - & - \\
\hline Punished in $t-1^{*}$ Intermittent 7 & $0.58(0.66)$ & - & - \\
\hline Punished in $t-1^{*}$ Intermittent 5 & $2.17 * * *(0.76)$ & - & - \\
\hline Punished in $t-1 *$ Intermittent 3 & $-0.10(0.61)$ & - & - \\
\hline Punished in $t-1^{*}$ Intermittent 7 with low fine & $0.09(0.52)$ & - & - \\
\hline Others' mean contribution in $t-1$ & $0.05^{* * *}(0.01)$ & $0.03 * * *(0.01)$ & $0.04 * * *(0.01)$ \\
\hline Loss aversion & $-0.04(0.03)$ & $<0.01(0.02)$ & $-0.03 * *(0.01)$ \\
\hline Risk index & $0.01(0.01)$ & $0.01(0.01)$ & $<0.01(0.01)$ \\
\hline Ambiguity aversion & $-0.01(0.02)$ & $<0.01(0.01)$ & $<0.01(0.01)$ \\
\hline Male & $0.09(0.08)$ & $-0.07(0.05)$ & $-0.05 *(0.03)$ \\
\hline Age & $<0.01(<0.01)$ & $<0.01(<0.01)$ & $<0.01(<0.01)$ \\
\hline Period & $<0.01(<0.01)$ & $<0.01(0.01)$ & $<0.01 *(<0.01)$ \\
\hline Constant & $-1.31 * * *(0.35)$ & $-0.41(0.27)$ & $-0.40 * *(0.16)$ \\
\hline Observations & 4,410 & 5,880 & 10,290 \\
\hline $\mathrm{R}^{2}$ & 0.16 & 0.08 & 0.09 \\
\hline
\end{tabular}

Note: Robust standard errors are in parentheses, clustered by group. All sessions included. ${ }^{* * *} p<0.01,{ }^{* *} p<0.05,{ }^{*} p<0.1,{ }^{\#} p<0.12$. 


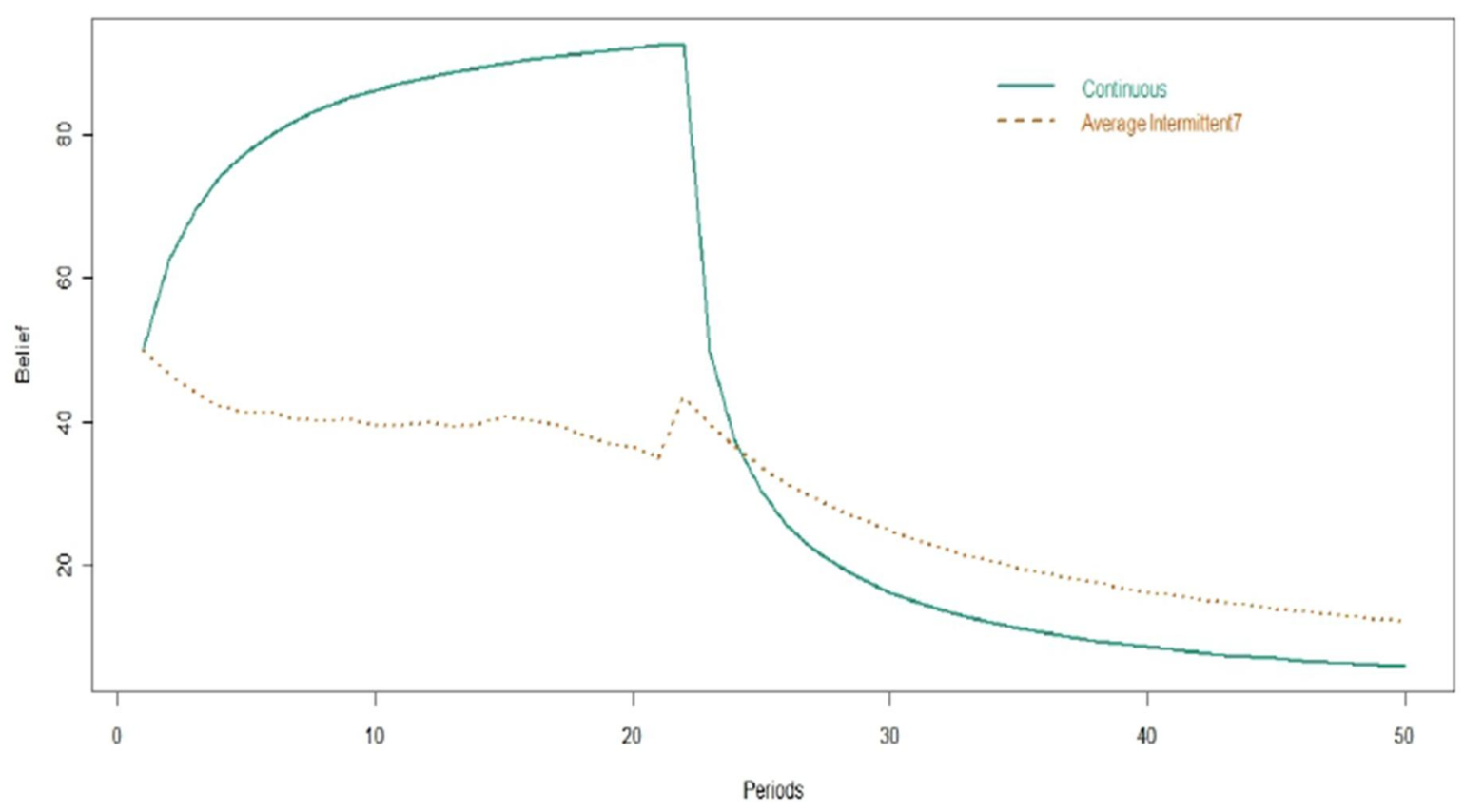

Fig. 1. Simulation of belief learning in the Continuous and Intermittent 7 treatments (with $\alpha=\beta=0.5$ in the Continuous treatment and $\alpha=\beta=0.2$ in the Intermittent 7 treatment) 

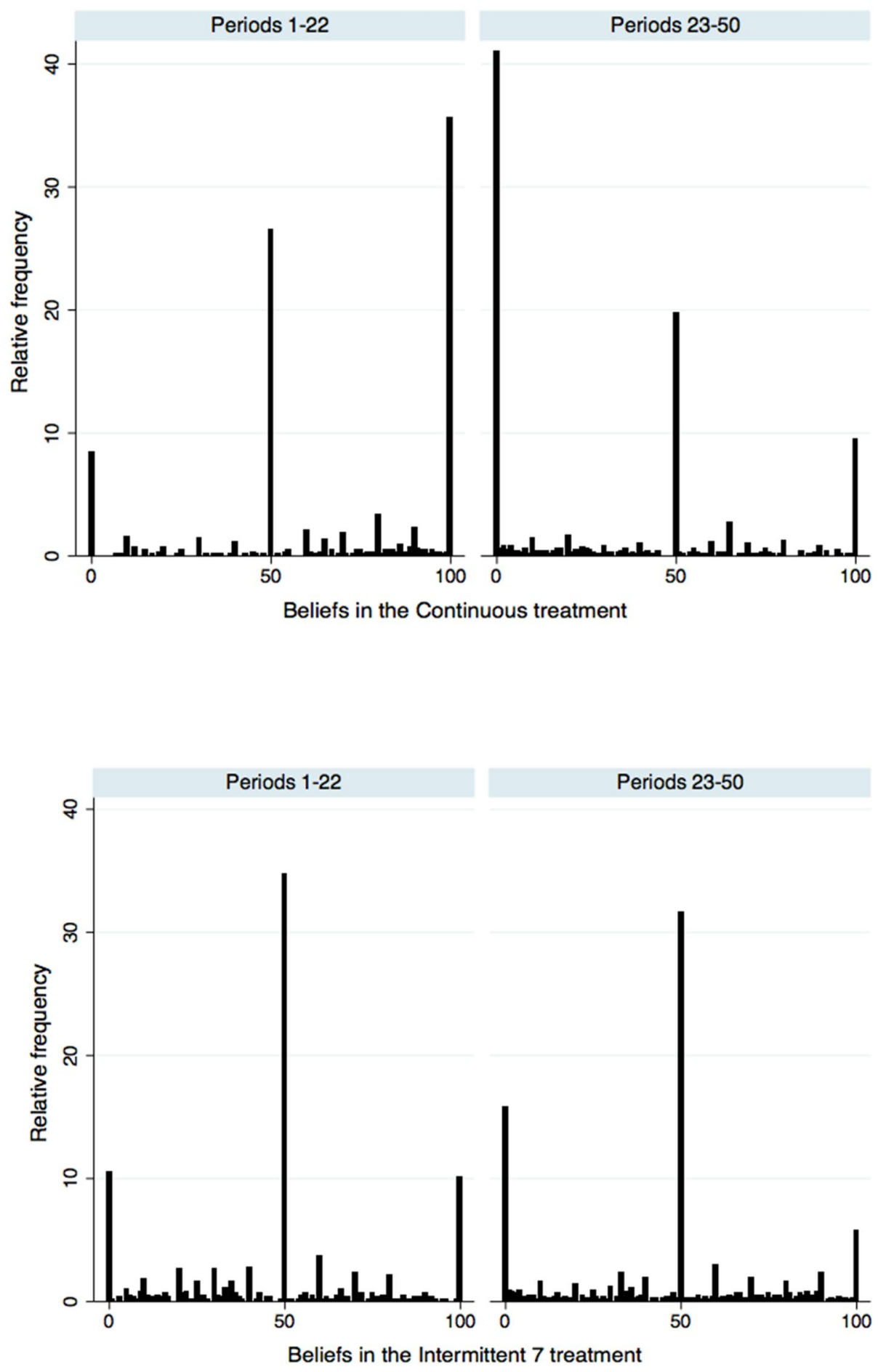

Fig. 2. Distribution of beliefs in the Continuous and Intermittent 7 treatments 


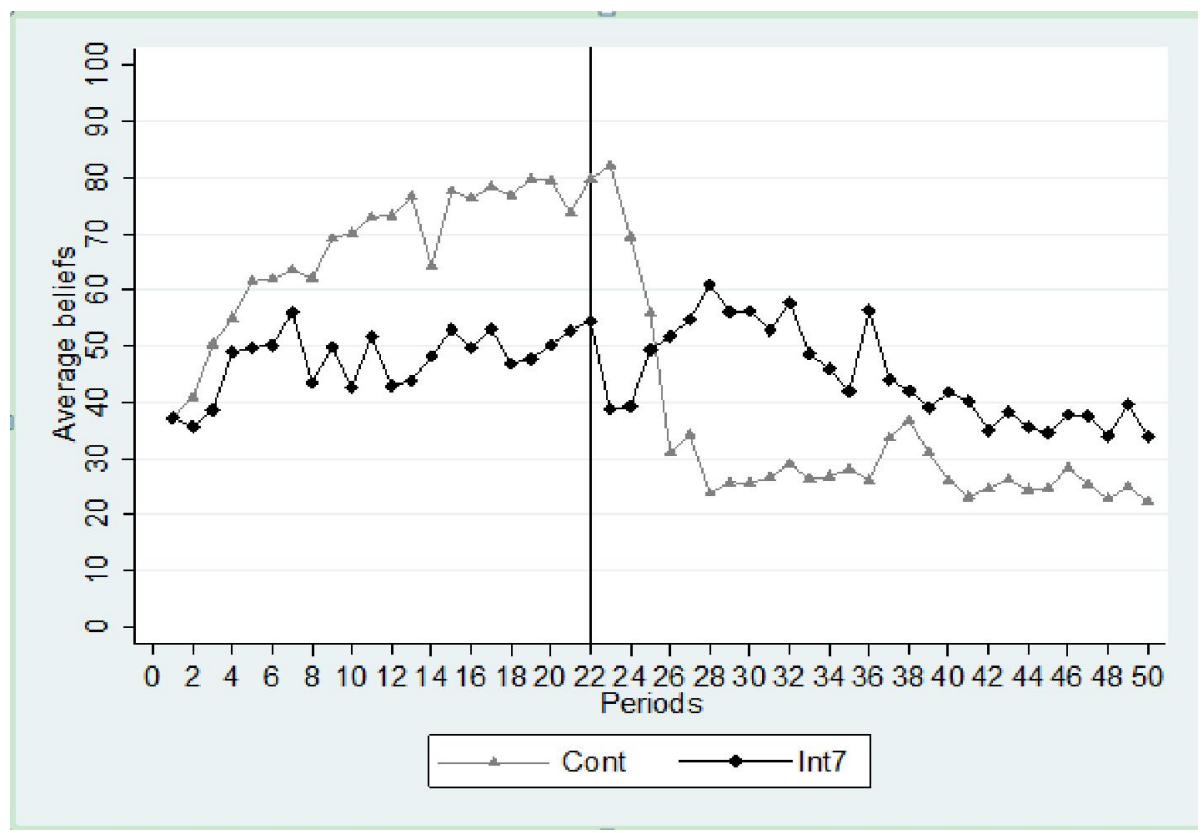

a) Continuous and Intermittent 7 treatments

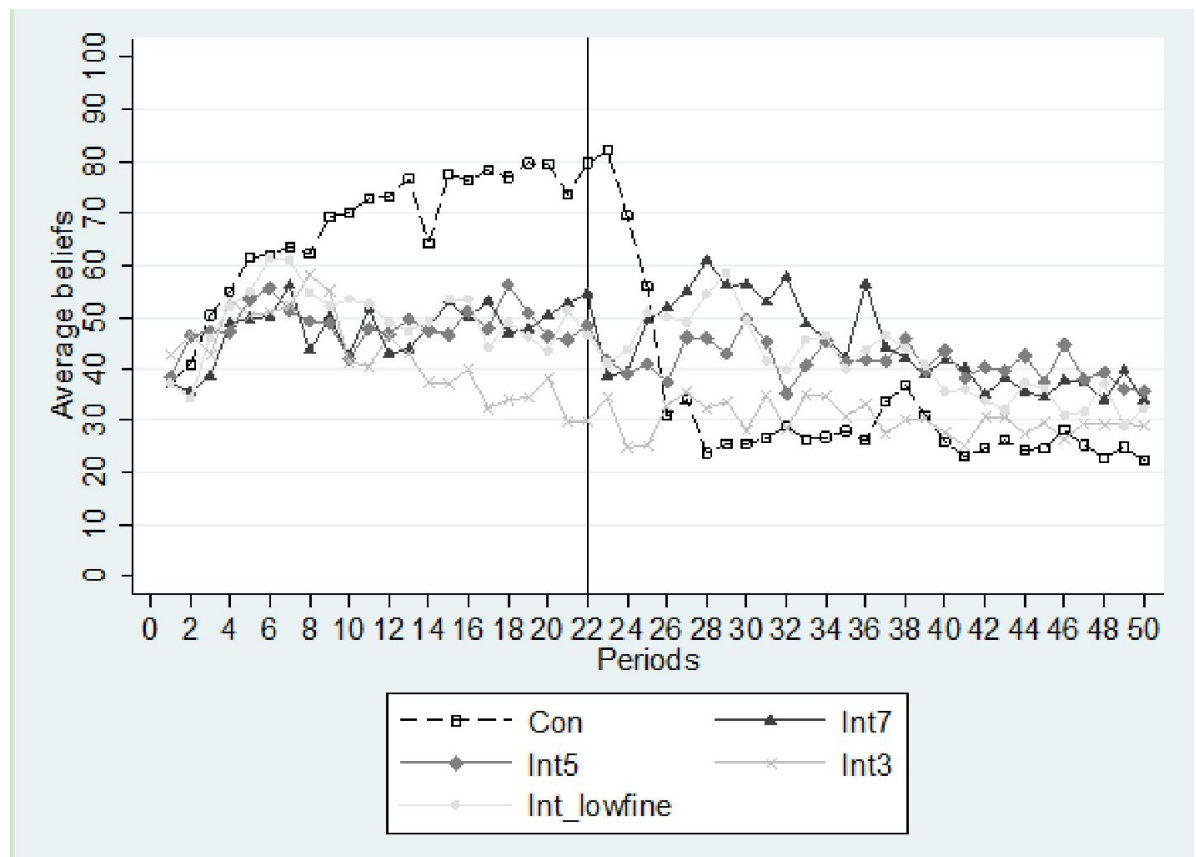

b) All treatments

Fig. 3. Evolution of beliefs over time

Note: The black bar in each graph indicates the period from which audits are definitely withdrawn. 


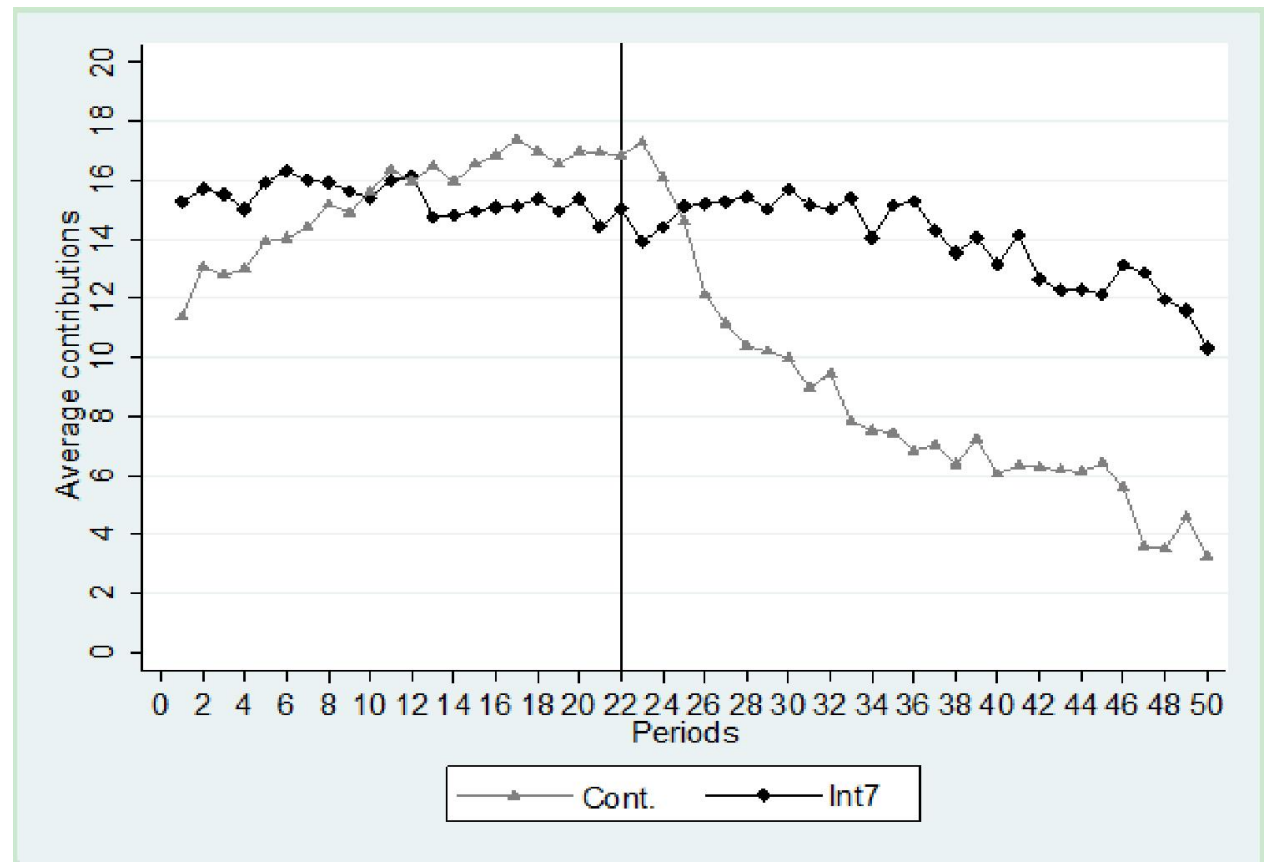

a) Continuous and Intermittent 7 treatments

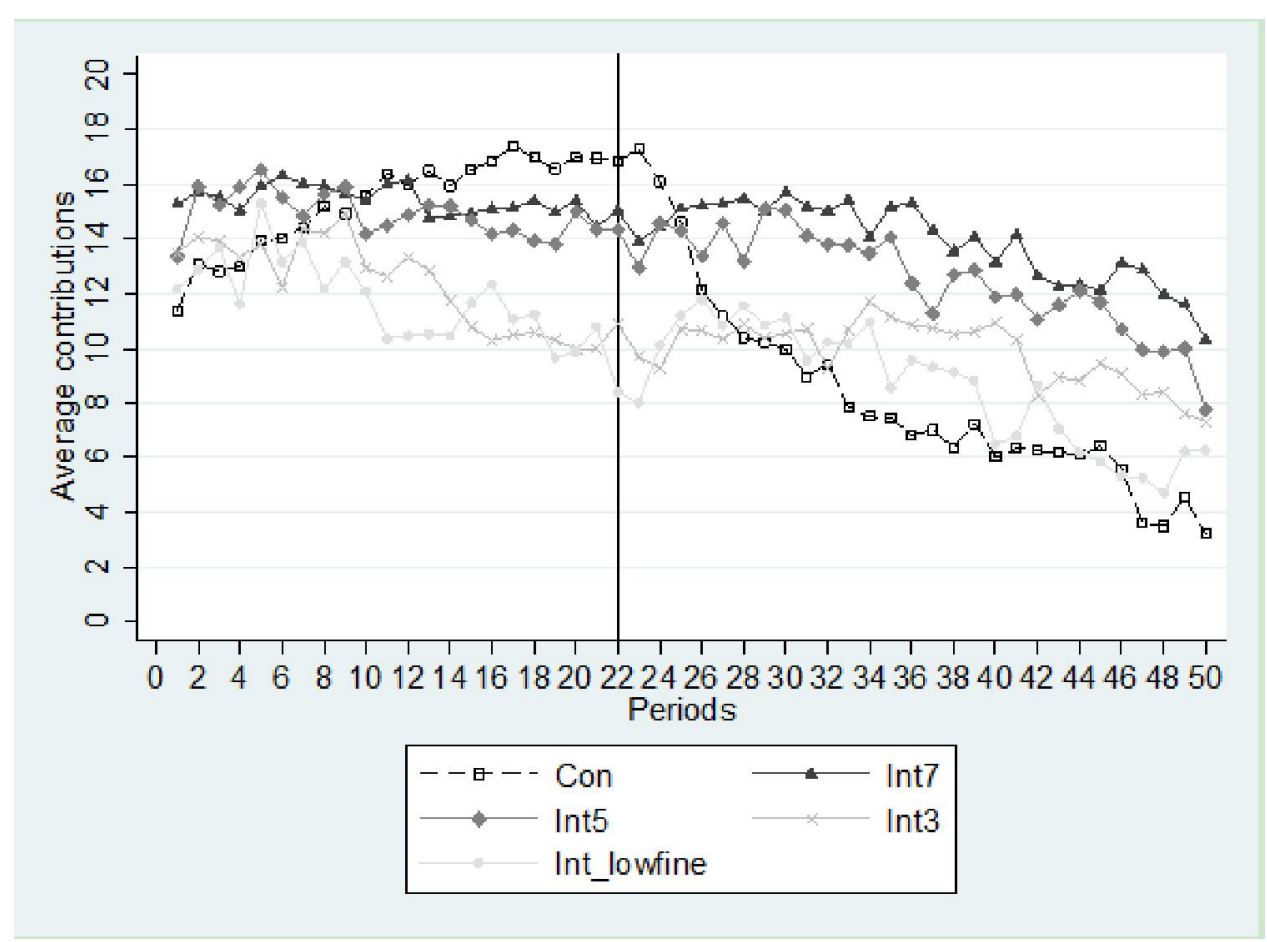

b) All treatments

Fig. 4. Evolution of contributions over time

Note: The black bar in each graph indicates the period from which audits are definitely withdrawn. 


\section{APPENDIX A. Proof}

Suppose that the mean contribution of the other group members is $\bar{c}_{-i}$. Player $i$ 's contribution can be presented either as:

$$
\bar{c}_{-i}+\alpha_{i} \text { if player } i \text { over-contributes by } \alpha_{i}, \alpha_{i}>0,
$$

or as:

$$
\bar{c}_{-i}-\beta_{i} \text { if player } i \text { under-contributes by } \beta_{i}, \beta_{i} \geq 0 .
$$

If player $i$ chooses to over-contribute, his payoff function can be written:

$$
\pi\left(\bar{c}_{-i}+\alpha_{i}\right)=20+0.5 \bar{C}_{-i}-0.5 \alpha_{i}
$$

This reaches a maximum when $\alpha_{i}=0$. Thus, player $i$ has no incentive to over-contribute.

If instead, player $i$ chooses to contribute less than his group members and if there is an audit, player $i$ will be punished. Suppose an audit occurs with probability $p . \delta$ is the fine parameter. Then, player $i$ 's payoff function becomes:

$$
\pi\left(\bar{C}_{-i}-\beta_{i}\right)=20+0.5 \bar{C}_{-i}+\left(0.5-\mathrm{p}^{*} \delta\right) \beta_{i}
$$

If $p$ is known, it pays to contribute less than the mean of others only when $p^{*} \delta<0.5$.

Thus, given the others' mean contribution, when $p^{*} \delta<0.5$ player $i$ 's best response is to free-ride completely $\left(\beta_{i}=20, c_{i}=0\right)$. Otherwise, if $p^{*} \delta \geq 0.5$, player $i$ should contribute exactly the same amount as the average of others $\left(c_{i}=\bar{c}_{-i}\right)$.

There are 20 Nash equilibria corresponding to each possible mean contribution. If we consider the concept of payoff dominance, it is clear that partial contribution will never maximize profits in this linear public goods game. Thus, full contribution is a payoff-dominant Nash equilibrium.

Since $\delta$ is common knowledge but $p$ is unknown, the player has to form beliefs about the value of $\mathrm{p}^{*} \delta$ that only depend on beliefs of the value of $p$. Let us assume that players have the same prior beliefs on the probability of being audited and expect that others have the same priors, and let us assume risk neutrality. In the Continuous treatment, players should all contribute 20 if they believe that $p$ is larger than 0.4 , and 0 otherwise. In the Intermittent 7 treatment, players should all contribute 20 if they believe that $p$ is larger is 0.13 , and 0 otherwise. 


\section{APPENDIX B. Instructions for the Continuous treatment (Original instructions in French)}

You are taking part in an experiment in economics during which you can earn money. Your earnings will depend on your decisions and on the decisions of the other participants with whom you will interact. It is therefore important to read these instructions with attention. You will also be given 4 Euros for showing-up on time.

This session consists of several independent parts. We have distributed the instructions for the first part; you will receive later the instructions for the next parts.

At the end of the session, your earnings from the various parts will be added. You will be paid individually and in cash in a separate room, by somebody who is not aware of the content of the experiment.

Throughout the session, it is strictly forbidden to communicate with the other participants.

\section{Part 1}

Your computer screen will present you successively with two urns that contain each ten balls, either yellow or blue.

○ The first urn contains 5 blue balls and 5 yellow balls.

○ The second urn contains also blue and yellow balls but in unknown proportions.

For each urn, you must make 20 successive choices between drawing a ball from the urn with replacement or earning a certain amount of money. If you draw a yellow ball from the urn, you earn $€$ 5; if you draw a blue ball from the urn, your earn $€ 0$.

We propose you 20 certain possible amounts, from $€ \mathbf{0 . 2 5}$ to $€ 5$, as shown in the Table below. For each urn, you must make a decision for each of the 20 proposals. Only one of these decisions will matter for determining your earnings in this part, as explained below.

Once you have completed each of the two tables, please validate your choice by pressing the "OK" button.

\begin{tabular}{|l|l|l|}
\hline 1 & O I choose the certain amount of $€$ 0.25 & O I choose to draw a ball \\
2 & O I choose the certain amount of $€$ 0.50 & O I choose to draw a ball \\
4 & O I choose the certain amount of $€$ 0.75 & O I choose to draw a ball \\
5 & O I choose the certain amount of $€ 1$ & O I choose to draw a ball \\
6 & O I choose the certain amount of $€ 1.25$ & O I choose to draw a ball \\
7 & O I choose the certain amount of $€ 1.50$ & O I choose to draw a ball \\
8 & O I choose the certain amount of $€ 1.75$ & O I choose to draw a ball \\
9 & O I choose the certain amount of $€ 2.25$ & O I choose to draw a ball \\
10 & O I choose the certain amount of $€ 2.50$ & O I choose to draw a ball \\
11 & O I choose the certain amount of $€ 2.75$ & O I choose to draw a ball \\
12 & O I choose the certain amount of $€ 3$ & O I choose to draw a ball \\
13 & O I choose the certain amount of $€ 3.25$ & O I choose to draw a ball \\
14 & O I choose the certain amount of $€ 3.50$ & O I choose to draw a ball \\
15 & O I choose the certain amount of $€ 3.75$ & O I choose to draw a ball \\
16 & O I choose the certain amount of $€ 4$ & O I choose to draw a ball \\
17 & O I choose the certain amount of $€ 4.25$ & O I choose to draw a ball \\
18 & O I choose the certain amount of $€ 4.50$ & O I choose to draw a ball \\
19 & O I choose the certain amount of $€ 4.75$ & O I choose to draw a ball \\
20 & O I choose the certain amount of $€ 5$ & O I choose to draw a ball \\
\hline
\end{tabular}

\section{How do we determine your earnings in this part?}

At the end of the session, the computer program will randomly determine which urn is used for payment. Next, for this urn, it will randomly draw a number between 1 and 20 to determine which of your 20 decisions will matter for determining your earnings.

- For this decision, if you have chosen the certain amount, this amount will be added up to your other earnings from the experiment. 
- If you have chosen to draw a ball, the computer program will draw the ball from the selected urn. If a yellow ball is drawn, $€ 5$ will be added to your other earnings from the experiment.

If you have any question regarding these instructions, please raise your hand and we will answer your questions in private.

\section{Instructions for Part 2 (distributed after completion of Part 1)}

In this part, you must make six successive choices on your computer between accepting and refusing to take part in a lottery with two possible outcomes: yellow or blue.

o If you refuse the draw, you win $€ 0$ and you lose $€ 0$.

o If you accept the draw, you win $€ 6$ if the computer program randomly draws the yellow color (which comes with a one in two chance) and you lose a certain amount if the computer program draws the blue color ( which happens with a one in two chance).

In each successive decision, the amount of the gain is always $€ 6$ and the amount of the loss ranges from $€ 2$ to $€ 7$. Your computer screen will display the following Table and you will make a decision on each line.

\begin{tabular}{|c|c|c|}
\hline & I accept & I reject \\
\hline 1. If Yellow is drawn, I earn $€ 6$. If Blue is drawn, I lose $€ 2$. & $\mathrm{O}$ & $\mathrm{O}$ \\
\hline 2. If Yellow is drawn, I earn $€ 6$. If Blue is drawn, I lose $€ 3$. & $\mathrm{O}$ & $\mathrm{O}$ \\
\hline 3. If Yellow is drawn, I earn $€ 6$. If Blue is drawn, I lose $€ 4$. & $\mathrm{O}$ & $\mathrm{O}$ \\
\hline 4. If Yellow is drawn, I earn $€ 6$. If Blue is drawn, I lose $€ 5$. & $\mathrm{O}$ & $\mathrm{O}$ \\
\hline 5. If Yellow is drawn, I earn $€ 6$. If Blue is drawn, I lose $€ 6$. & $\mathrm{O}$ & $\mathrm{O}$ \\
\hline 6. If Yellow is drawn, I earn $€ 6$. If Blue is drawn, I lose $€ 7$. & $\mathrm{O}$ & $\mathrm{O}$ \\
\hline
\end{tabular}

Please look at the first line. In this line, you choose between accepting and rejecting a draw which gives $1 / 2$ chance to win $€ 6$ and $1 / 2$ chance to lose $€ 2$. In the next line, you choose between accepting and rejecting a draw which gives $1 / 2$ chance to win $€ 6$ and the same chance to lose $€ 3$. And so on until the $6^{\text {th }}$ decision.

\section{How we determine your earnings in this part?}

At the end of the session, the computer program will randomly choose one of your six decisions. o If you have refused to draw for this decision, your gain for this part is $€ 0$.

o If you have accepted to draw for this decision, the program randomly draws one of two colors. If the yellow color is drawn, your gain for this part is $€ 6$ that will be added to your other earnings in the session. If the blue color is drawn, you will lose a certain amount that will be deducted from your other earnings in the session.

If you have any questions about this instruction, raise your hand and we will answer these questions in private.

\section{Instructions for Part 3 (distributed after completion of Part 2)}

This part consists of 50 periods.

All the transactions during this part are conducted in ECU (Experimental Currency Units), according to the following rules:

- Your total payoff in ECU for this part consists of the sum of your payoffs in each of the 50 periods comprising this part.

$\circ \quad$ ECU will be converted into Euros at the rate: $150 \mathrm{ECU}=1$ Euro. 
At the end of the session, the total amount of ECU you have earned during this part will be converted to Euros and added to your other earnings.

At the beginning of this part, the participants are divided into groups of three. You will therefore interact with two other participants. During the 50 periods, you will interact with the same persons. You will never be informed of the identity of these persons.

\section{Description of each period}

At the beginning of each period, each group member receives an endowment of 20 ECU.

The three participants belonging to a group can participate in a project by investing in a public account that will be shared equally among them. The amount of this public account is determined by the sum of the individual investments of the three members of the group.

In some periods, the group members' investments can be reviewed by the computer program. In case of a review, if a group member has invested less than the average of the two other group members, his payoff is reduced.

The details of each period are described below.

1) You receive an endowment of 20 ECU. You, as well as the two other group members, simultaneously decide how much of your endowment you will invest in the public account, by indicating a number between 0 and 20. The amount of your endowment that is not invested in the public account is assigned to your private account. To validate your choice, you must press the OK button.

After all group members have made their decision, your screen will display the total amount of ECU invested in the project by the group members (including your own investment).

Your payoff consists of two parts:

- the amount of your endowment that you have kept for yourself in your private account (i.e. 20 - your investment),

- the income from the project: this income represents $50 \%$ of the total investment of all three group members in the public account.

Your payoff in ECU is computed as follows:

$(20$ - your investment $)+50 \% *$ (total investment of the group)

The payoff of each group member is calculated in the same way, which means that each group member receives the same income from the project.

Suppose the total investment of all group members is $50 \mathrm{ECU}$. In this example each member of the group receives an income from the project of $50 \%$ of $50 \mathrm{ECU}=25 \mathrm{ECU}$. If the total investment is $10 \mathrm{ECU}$, then each member of the group receives an income of $50 \%$ of $10 \mathrm{ECU}=5 \mathrm{ECU}$ from the project.

For each ECU of your endowment that you keep on your private account you earn an income of 1 ECU. Every ECU you invest in the public account instead increases the total investment by one ECU. The income from the project will increase by $0.5 \mathrm{ECU}$ per person and so, the total income of the group from the project rises by $1.5 \mathrm{ECU}$. This means that your investment in the public account also increases the income of the other group members.

On the other hand you will earn money from each ECU invested by the other members in the project. For each ECU invested by any group member you earn $50 \%(1)=0.5 \mathrm{ECU}$.

2) In some periods, the investments of the group members are reviewed by the computer. You do not know in advance which periods are reviewed and how many periods are reviewed.

- If there is no review, the period ends and your payoff of the period is not modified.

○ In case of a review, there are two possible situations.

- If you have invested in the public account less than the average investment of the two other group members, your payoff is reduced. The payoff reduction amounts to 1.25 times the difference between the mean investment of the two other group members and your investment. 
- If you have invested the same amount or more than the average investment of two other group members, your payoff is not modified.

To recapitulate, in each period, your payoff in ECU is calculated as follows:

- $(20$ - your investment $)+50 \% *$ (total investment of the group) $-1.25 *$ (mean investment of the two other group members - your investment) in case of a review and if your investment is lower than the average investment of the two other members

- $(20$ - your investment $)+50 \% *$ (total investment of the group), otherwise

In periods with a review, your payoff can be negative. In case your payoff would be negative at the end of the 50 periods, this loss would be deducted from your other earnings.

3) At the beginning of each period, before you choose your investment, we ask you to estimate the number of chances (from 0 to 100) that the investments will be reviewed at the end of this period. For example, if you believe that there are $\mathrm{X}$ chances out of 100 that they will be reviewed, then enter the number $\mathrm{X}$.

At the end of the session, the computer program will randomly draw one of the 50 periods and it will compare your prediction to the existence or not of a review in this period. You will receive an additional payoff that will depend on the precision of your estimate. We will pay you for your prediction as follows:

Suppose you predict that there are 20 chances out of 100 that there will be a review and therefore 80 chances out of 100 that there will be no review. Suppose now that there was actually no review in this period. In that case, your payoff will be

$$
\text { Prediction payoff }=\left[2 \text { Euro }-\left(1-\frac{80}{100}\right)^{2}-\left(\frac{20}{100}\right)^{2}\right]
$$

In other words, we will give you a fixed amount of 2 Euros from which we will subtract an amount that depends on how inaccurate your prediction was. To do this, when we find out whether a review occurred or not, we will take the number you assigned to the situation that actually occurred, in this case $80 \%$ for no review, subtract if from $100 \%$ and square it. We will then take the number you assigned to the situation that did not occur, in this case the $20 \%$ that you assigned to review, and square it also. These two squared numbers will then be subtracted from the 2 Euros we initially gave you to determine your final prediction payoff.

Note that the worst you can do under this payoff scheme is to state that you believe that there is a $100 \%$ chance that a certain situation will occur and assign $100 \%$ to that situation when in fact the other situation actually occurs. Here your payoff from prediction will be 0 . Similarly, the best you can do is to guess correctly and assign $100 \%$ to that situation which turns out to be the actual situation. Here your payoff will be 2 Euros.

However, since your prediction is made before you know whether there is a review or not in the period, the best thing you can do to maximize the expected size of your prediction payoff is to simply state your true belief about the number of chances there will be a review or not. Any other prediction will decrease the amount you can expect to earn as a prediction payoff.

We will pay your prediction in one of the 50 periods. As you do not know in advance which period will be randomly selected at the end of the session for payment of prediction payoff, please pay the same attention to each of your 50 predictions.

4) Information

After all group members have made their prediction and their investment decision, you are informed about the total amount invested in the public account.

You also learn whether the investments were reviewed or not, whether your payoff has been reduced and by how much, and your final payoff for the period.

You are not informed whether other group members' payoffs have been reduced and their final payoffs. 
At the end of a period, the next period starts automatically. You receive a new endowment of 20 ECU, you report your prediction about the existence of a review in this period, and you decide on your investment in a public account.

After completing the 50 periods, you will be asked to answer a final brief questionnaire. Then, you will be invited to leave the room and to proceed to the payment room.

Please read these instructions again and answer the questionnaire that has been distributed; we will check your answers individually. If you have any questions about these instructions, please raise your hand. We will answer your questions in private. 